Florida International University FIU Digital Commons

FIU Electronic Theses and Dissertations

University Graduate School

3-27-2015

\title{
Essays on Competition in the Pharmaceutical Industry
}

Jiangyun Wan

jiangyun.wan@gmail.com

DOI: $10.25148 /$ etd.FI15032133

Follow this and additional works at: https://digitalcommons.fiu.edu/etd

Part of the Econometrics Commons, Health Economics Commons, and the Industrial Organization Commons

\section{Recommended Citation}

Wan, Jiangyun, "Essays on Competition in the Pharmaceutical Industry" (2015). FIU Electronic Theses and Dissertations. 1900. https://digitalcommons.fiu.edu/etd/1900

This work is brought to you for free and open access by the University Graduate School at FIU Digital Commons. It has been accepted for inclusion in FIU Electronic Theses and Dissertations by an authorized administrator of FIU Digital Commons. For more information, please contact dcc@fiu.edu. 


\section{FLORIDA INTERNATIONAL UNIVERSITY \\ Miami, Florida}

A dissertation submitted in partial fulfillment of the

requirements for the degree of DOCTOR OF PHILOSOPHY

in

ECONOMICS

by

Jiangyun Wan 
To: Dean Michael R. Heithaus

College of Art and Science

This dissertation, written by Jiangyun Wan, and entitled Essays on Competition in the Pharmaceutical Industry, having been approved in respect to style and intellectual content, is referred to you for judgment.

We have read this dissertation and recommend that it be approved.

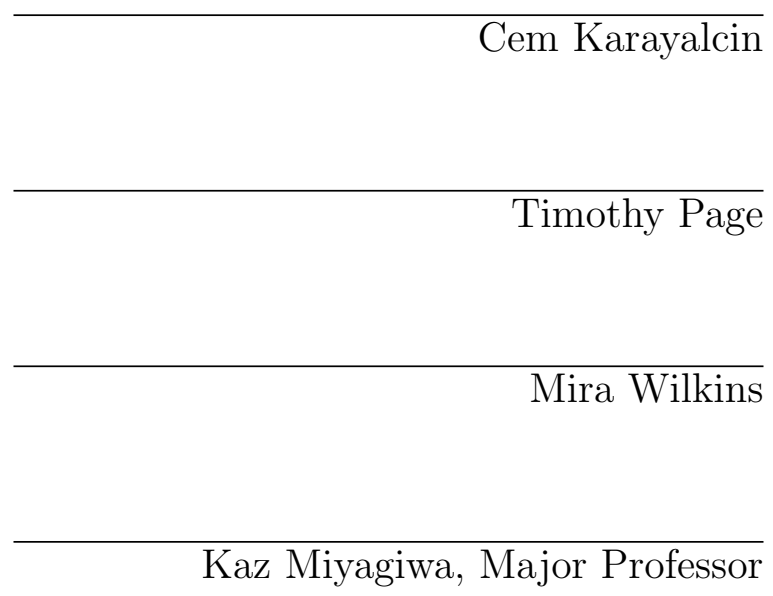

Date of Defense: March 27, 2015

The dissertation of Jiangyun Wan is approved.

\begin{tabular}{r}
\hline $\begin{array}{r}\text { Dean Michael R. Heithaus } \\
\text { College of Art and Science }\end{array}$ \\
\hline Dean Lakshmi N. Reddi \\
University Graduate School
\end{tabular}

Florida International University, 2015 
(C) Copyright 2015 by Jiangyun Wan All rights reserved. 


\section{DEDICATION}

To my parents. 


\section{ACKNOWLEDGMENTS}

I wish to thank all the members of my dissertation committee, Professors Karayalcin, Page and Wilkins, especially Professor Miyagiwa, my dissertation supervisor, for their support and guidance while I was completing my dissertation. 


\author{
ABSTRACT OF THE DISSERTATION \\ ESSAYS ON COMPETITION IN THE PHARMACEUTICAL INDUSTRY \\ by \\ Jiangyun Wan \\ Florida International University, 2015 \\ Miami, Florida \\ Professor Kaz Miyagiwa, Major Professor
}

Chapter 1: Patents and Entry Competition in the Pharmaceutical Industry: The Role of Marketing Exclusivity

Effective patent length for innovation drugs is severely curtailed because of extensive efficacy and safety tests required for FDA approval, raising concern over adequacy of incentives for new drug development. The Hatch-Waxman Act extends patent length for new drugs by five years, but also promotes generic entry by simplifying approval procedures and granting 180-day marketing exclusivity to a first generic entrant before the patent expires. In this paper we present a dynamic model to examine the effect of marketing exclusivity. We find that marketing exclusivity may be redundant and its removal may increase generic firms' profits and social welfare. Chapter 2: Why Authorized Generics?: Theoretical and Empirical Investigations Facing generic competition, the brand-name companies some-times launch generic versions themselves called authorized generics. This practice is puzzling. If it is cannibalization, it cannot be profitable. If it is divisionalization (Baye et al., 1996), it should be practiced always instead of sometimes. I explain this phenomenon in terms of switching costs in a model in which the incumbent first develops a customer base to ready itself against generic competition later. I show that only sufficiently low switching costs or large market size justifies launch of AGs. I then use prescription drug data to test those results and find support. 
Chapter 3: The Merger Paradox and R\&D

Oligopoly theory says that merger is unprofitable, unless a majority of firms in industry merge. Here, we introduce $R \& D$ opportunities to resolve this so-called merger paradox. We have three results. First, when there is one R\&D firm, that firm can profitably merge with any number of non-R\&D firms. Second, with multiple R\&D firms and multiple non-R\&D firms, all R\&D firms can profitably merge. Third, with two $R \& D$ firms and two non-R\&D firms, each $R \& D$ firms prefer to merge with a non-R\&D firm. With three or more than non-R\&D firms, however, the R\&D firms prefer to merge with each other. 


\section{TABLE OF CONTENTS}

1. PATENTS AND ENTRY COMPETITION IN THE PHARMACEUTICAL INDUSTRY: THE ROLE OF MARKETING EXCLUSIVITY . . . . . . . 1

1.1 Introduction . . . . . . . . . . . . . . . . . . . 1

1.2 Hatch-Waxman and generic entry promotion . . . . . . . . . . . . . 5

1.3 Model . . . . . . . . . . . . . . . . . . . . . . . . 7

1.4 The Counterfactual: Hatch-Waxman without marketing exclusivity . . . 9

1.4.1 Two challengers in period $1 \ldots \ldots \ldots$

1.4 .2 One challenger in period $1 \ldots \ldots \ldots \ldots$

1.4 .3 No challengers in period $1 \ldots \ldots \ldots \ldots$

1.4 .4 Equilibrium in period $1 \ldots \ldots \ldots \ldots$

1.5 Marketing exclusivity . . . . . . . . . . . . . . . . . . . . 15

1.5.1 Two challengers in period $1 \ldots \ldots \ldots \ldots$

1.5 .2 One challenge in period $1 \ldots \ldots \ldots \ldots \ldots$

1.5.3 No challenges in period $1 \ldots \ldots \ldots$

1.5.4 Equilibrium in period $1 \ldots \ldots \ldots$

1.6 The effect of marketing exclusivity _ . . . . . . . . . . . . . 20

1.7 The welfare effect of marketing exclusivity . . . . . . . . . . . 26

1.7.1 Marketing exclusivity . . . . . . . . . . . . . . . . . . 27

1.7.2 No marketing exclusivity . . . . . . . . . . . . . . . . . . . . . 27

1.7.3 The welfare impact of marketing exclusivity . . . . . . . . . . . 28

1.8 Concluding remarks . . . . . . . . . . . . . . . . . . . . . . . . . . . . . . . . . . . 29

2. WHY AUTHORIZED GENERICS?: THEORETICAL AND EMPIRICAL

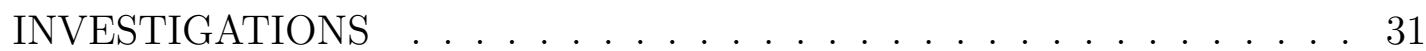

2.1 Introduction . . . . . . . . . . . . . . . . . . . . . . 31

2.2 Competitions Without AG . . . . . . . . . . . . . . . 36

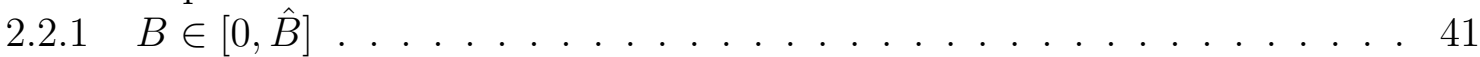

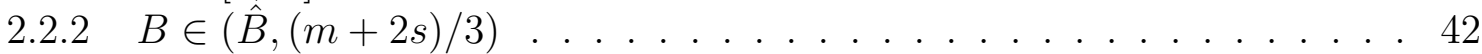

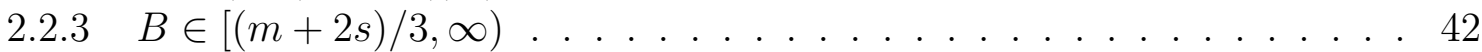

2.2 .4 Global maxima without AG . . . . . . . . . . . . . . . 43

2.3 With $\mathrm{AG} \ldots \ldots \ldots \ldots \ldots \ldots \ldots \ldots$

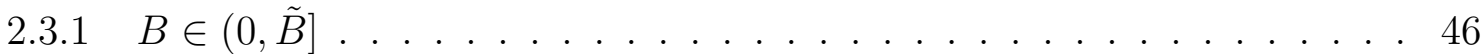

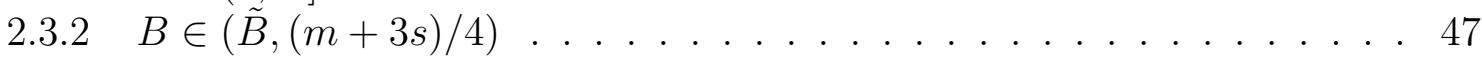

$2.3 .3 \quad B \in[(m+3 s) / 4, \infty) \ldots \ldots \ldots \ldots \ldots \ldots$

2.3.4 Global Maxima with AG . . . . . . . . . . . . . . . . . . . . . 48

2.4 Comparisons . . . . . . . . . . . . . . . . . . . . . . . . . . . . . 49

2.5 Empirical investigations . . . . . . . . . . . . . . . . 50

2.5 .1 Data . . . . . . . . . . . . . . . . . . . . 50

2.5.2 Methodology . . . . . . . . . . . . . . . . . . 54 


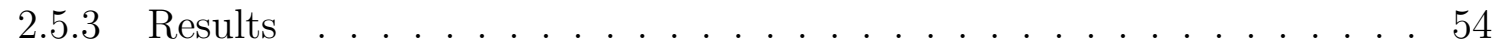

2.6 Conclusions . . . . . . . . . . . . . . . . . . 56

3. THE MERGER PARADOX AND R\&D . . . . . . . . . . . . . 58

3.1 Introduction . . . . . . . . . . . . . . . . . . . 58

3.2 A single R\&D firm and merger . . . . . . . . . . . . . . . 60

3.3 Multiple R\&D firms and merger . . . . . . . . . . . . . . . . 64

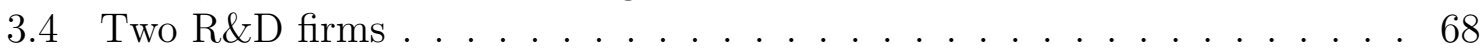

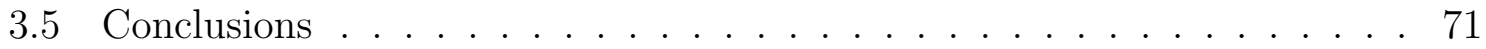

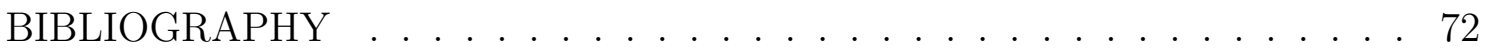

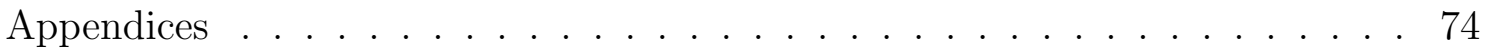

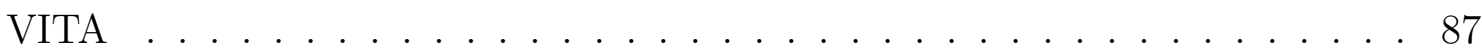




\section{LIST OF FIGURES}

FIGURE

PAGE

1.1 Equilibrium Without Marketing Exclusivity . . . . . . . . . . . . . . 15

1.2 Equilibrium With Marketing Exclusivity . . . . . . . . . . . . . . 20

1.3 Equilibrium With/out Marketing Exclusivity: Comparisons . . . . . . . 21

$2.1 \quad g$ is relatively small so that $B \leq \hat{b}(g) \ldots \ldots$. . . . . . . . . . 38

$2.2 g$ is intermediate so that $\hat{b}(g)<B<\bar{b}(g) \ldots \ldots . \ldots . \ldots$

$2.3 g$ is large so that $\bar{b}(g) \leq B \ldots \ldots . \ldots \ldots$

2.4 The incumbent's best-response function . . . . . . . . . . . . . . . . 40

A.1 $\delta \leq\left(\Pi^{T}-\Pi^{D} / 2\right) /\left(\Pi^{D}-\Pi^{T}\right) \ldots \ldots \ldots \ldots \ldots$

A.2 $\delta>\left(\Pi^{T}-\Pi^{D} / 2\right) /\left(\Pi^{D}-\Pi^{T}\right) \ldots \ldots \ldots \ldots \ldots . \ldots \ldots$ 
CHAPTER 1

\section{PATENTS AND ENTRY COMPETITION IN THE PHARMACEUTICAL INDUSTRY: THE ROLE OF MARKETING EXCLUSIVITY}

\section{$1.1 \quad$ Introduction}

The patent system strikes a delicate balance between the need to spur innovation and the desire to disseminate it in society. To this end a patent gives an inventor the exclusive rights to the innovation for a limited period - currently 20 years. For new drugs, however, the effective patent length is about half as long because of the lengthy review process they must undergo prior to get approval from the FDA (U.S. Food and Drug Administration). This review process requires preclinical (laboratory and animal) and clinical (human) tests for efficacy, safety, side effects and reactions from long-time use, ${ }^{1}$ and typically takes 12 to 13 years, severely curtailing the effective patent length for branded drugs and raising concern for the inadequacy of incentives for the development of new drugs in the U.S. (Mossinghoff, 1999). Merely extending patent length for innovation drugs, however, delays entry of generic drugs and raises another concern; higher costs of medicines, which hurts consumers. ${ }^{2}$ Efforts to walk a fine line between these conflicting problems resulted in the enactment

\footnotetext{
${ }^{1}$ The 1962 Kefauver-Harris Drug Amendments require both safety and efficacy for any new drugs to be approved for marketing by FDA. Especially, controlled pre-clinical and clinical tests must be set up to systematically demonstrate the safety and efficacy (FDA 100 years).

${ }^{2}$ Generic entry is likely to be affected by non-profit factors. Recent work by Iizuka (2008) and Iizuka (2012), for example, use micro panel data from the Japanese pharmaceutical markets to demonstrate the sensitivity of generic entry to the prescription pattern, especially, to physicians' failure to internalize cost differences offered by generics.
} 
of the 1984 Drug Price Competition and Patent Term Restoration Act, commonly known as the Hatch-Waxman Act.

The Hatch-Waxman Act addresses both concerns noted above as follows. To simulate innovation, it extends patent length for additional five years. To promote generic entry, it takes a two-pronged approach. Firstly, it lowers entry costs for generics by streamlining the review process for FDA approval; see section 2 below for more on this. Secondly, it encourages generic drug producers to challenge the patents of the branded drugs. To that effect, Hatch-Waxman grants a first successful generic entrant with marketing exclusivity for 180 days. In short, Hatch-Waxman restores the incentives to develop new drugs with patent length extension but also diminishes such incentives by promoting generic penetration. Thus, its overall impact on innovation incentives is opaque. In this paper we investigate this issue.

More specifically, in this paper we focus on the role of the marketing exclusivity provision. This provision promotes early generic entry but also limits competition among generics. Thus, it may have both pro-competitive and anti-competitive effects, just like Hatch-Waxman or the patent system itself.

Our analysis utilizes a multi-period model with three firms: one branded drug company and two generic firms. We suppose that initially the branded drug company markets its product under the patent, while generic drug companies are not yet in the market. To enter, each generic firm must go through the review process for FDA approval of their products. We assume that this process is not too costly to prevent entry by both firms when the branded drug's patent expires. This puts the focus of our analysis on the generic firms' entry strategies before the patent expires and hence in the threat of infringement litigation by the branded drug company.

Our model features two key aspects of patent infringement litigation. A first assumption is that litigation is stochastic. This assumption reflects the dominant 
view among economists and legal scholars. For example Lemely and Shapiro (2005) observe that a patent "does not confer upon its owner the right to exclude but a right to try to exclude by asserting the patent in court" (p. 75) and continues thus: "When the patent holder asserts the patent against an alleged infringer, the patent holder is throwing the dice. If the patent has been found invalid, the property right has been evaporated" (p. 75)

A second key assumption of our model is that litigation is time-consuming. Although it is usually assumed away in the literature, ${ }^{3}$ lengthy litigation is a fact of life, and it is especially important in the pharmaceutical industry. Because the FDA in principle does not approve generic drugs before patent litigation disputes are settled, the branded drug company can always delay generic entry by taking a generic challenger to court.

We now outline our model. To present a simple tractable model while still capturing the relevant features of the environment for our issue, we assume that the incumbent's patent expires at the beginning of the third period and focus on the generic firms' entry decisions in the first two periods. To model the time-consuming litigation process, we assume that litigation takes one whole period. Thus, by filing infringement, the incumbent is assured of the monopoly profit for at least one period. If the patent is found invalid at the end of that period, FDA immediately approves marketing of generics, whereas, if the patent is found valid, generic firms must wait till the patent expires to enter. ${ }^{4}$

To evaluate the effect of marketing exclusivity, we consider two scenarios. One scenario is factual; Hatch-Waxman contains the marketing exclusivity provision so,

\footnotetext{
${ }^{3}$ See, e.g., Choi (1998) and Lemely and Shapiro (2005).

${ }^{4}$ We assume as in Choi (1998) that, when declared valid, the patent remains valid for the remainder of its life.
} 
although both generic firms may challenge the patent, at most one can successfully enter. A second scenario is counterfactual; there is no market exclusivity, so both generic firms are allowed to enter if the patent is found invalid. We then compare the equilibrium outcomes of these two scenarios to determine the effect of the marketing exclusivity provision.

To get an intuitive understanding of the effect of marketing exclusivity, consider the counterfactual scenario. Suppose that one generic firm challenges the patent. If the incumbent files suit for patent infringement, this generic firm must wait one period and still faces the risk of entry denied since the patent may be valid. A nonchallenger, on the other hand, enters only if the patent was invalid, and hence faces no risk confronting the challenger. Thus, in the counterfactual scenario, generic firms may play a waiting game. In contrast, with marketing exclusivity, only one generic firm can enter even the patent is invalid. Thus, with marketing exclusivity generic firms may compete to be the first - and the only one - to compete with the incumbent; that is, they may play a preemption game. In a word, marketing exclusivity can be pro-competitive as regards generic entry but anti-competitive as regards the incumbent.

Our main results can now be summarized as follows. Firstly, without marketing exclusivity at most one generic firm challenges the patent. With marketing exclusivity, there is the range of entry cost in which both generic firms challenge the patent. However, since only one generic is allowed entry with marketing exclusivity, either scenario has at most one entrant before the patent expires. However, with marketing exclusivity generic firms are more willing to challenge the patent even if entry costs are higher.

Secondly, marketing exclusivity produces contrasting effects on the profits of the incumbent and generic firms. When entry costs are low, marketing exclusivity 
benefits the incumbent and hurts generics. When entry costs are high, marketing exclusivity hurts the incumbent and benefits generic firms. Interestingly enough, when entry costs are in the intermediate range, all firms can benefit from having marketing exclusivity. Thus, marketing exclusivity may serve as a collusive device between the incumbent and generic entrants.

Thirdly, the welfare effect of marketing exclusivity may not be monotonic. While it can lower social welfare at all entry cost, it is possible that when the entry cost is in the intermediate range social welfare can be greater with marketing exclusivity than without it.

The remainder of this paper is organized in 7 sections. Section 1.2 provides additional information about entry promotion under the Hatch-Waxman Act. Sections 1.3 and 1.4 presents the multi-period model of generic entry without marketing exclusivity and with marketing exclusivity, respectively. Section 1.5 compares the results obtained in sections 1.3 and 1.4. Section 1.6 examines effect of marketing exclusivity on both the incumbent and generic firms. Section 1.7 examines the welfare effect of marketing exclusivity. The final section concludes.

\subsection{Hatch-Waxman and generic entry promotion}

In this section we provide additional background information about generic entry promotion under Hatch-Waxman. As mentioned already, Hatch-Waxman takes a two-pronged approach to generic entry promotion. One is by reducing entry costs for generics. A previous effort to do so, under the 1962 Kefauver-Harris Drug Amendments, allowed generics (approved before 1962) to demonstrate the safety

solely through published research results versions of innovation drugs. Despite this change, there was no generic entry for 150 drugs that went off the patents after 1962 
(Mossinghoff, 1999). This fact shows that even to run "paper-based" tests for safety can be too costly for generic entry.

It is estimated that the cost of bringing a new drug to market ranges between 500 million and 1000 million dollars, and over $80 \%$ of R\&D resources are allocated to the preclinical (animal tests) and clinical (human tests) periods. ${ }^{5}$ Thus, it was imperative to further streamline the testing process for generics. Now, a new process called the Abbreviated New Drug Application (ANDA) process, exempts generics from both pre-clinical and clinical tests, and requires only the bioequivalence tests for FDA approval (Mossinghoff, 1999).

Furthermore, previously, innovation drug data were kept as trade secrets and were made available fives years after innovation drugs were first marketed. Now, brand-name drug data are available for generics firms to prove the safety and efficacy of their products, further reducing the entry costs for them.

We now turn to the second prong of generic entry promotion in Hatch-Waxman, the 180-day marketing exclusivity provision. To be granted marketing exclusivity, a generic company must challenge the branded drug's patent. We first give a brief description of the process of challenging the patents on innovation drugs and then explain what exclusivity does to promote patent challenges. When challenging the patent, a generic firm must file an ANDA to the FDA with a Paragraph IV certification, thereby claiming the invalidity of the patent, and also notify the patent holder of this claim at the same time. Following such a notification, the patent holder has 45 days to decide whether to file patent infringement suit. If the patent holder sues the challenger, the FDA automatically stays approval of the generic drug

\footnotetext{
${ }^{5}$ Strategic Balancing of Patent and FDA Approval Process to Maximize Market Exclusivity (FDA poster)
} 
for 30 months. $^{6}$ If the patent holder wins the litigation suit, the patent is upheld and generic entry is denied. If the patent is found invalid, FDA approval is granted immediately for the generic. Given the risk of invalidation, the patent holder may prefer to take no legal actions against the challenger within the 45-day period. In this case, the generic producer is given FDA approval at the end of the 45-day period. Even so, the patent holder reserves the right to sue the generic producer later. $^{7}$

\subsection{Model}

We consider a multi-period model of competition between an incumbent and two potential entrants. Periods run from 1 to infinity. All actions take place at the beginning of periods. All firms face the common discount factor denoted by $\delta$ $(\delta<1)$. At period 1 the incumbent is already a well-established manufacturer of a branded drug. Two potential entrants are generic drug producers. To bring its product to the market, each generic firm must incur the entry cost $F(F>0)$, which covers the cost to obtain FDA approval. The incumbent's patent is assumed to expire at the end of the second period. Thus, generic firms can enter in period 3 or later without fear of patent infringement. In contrast, if they attempt entry in periods 1 or 2 , they must challenge the patent and face patent infringement litigation.

Consumers regard the branded drug and its generic versions as homogenous in quality. Moreover, all firms are assumed to use identical technologies to manufacture

${ }^{6}$ More specifically, FDA approval for marketing the generic drug is automatically stayed for 30 months or until the court returns a verdict or until the patent expires, whichever comes first.

${ }^{7}$ See Choi (1998) for more on this. 
their products. Thus, when there is entry, each active firm receives an identical profit, $\Pi^{D}$ or $\Pi^{T}$, denoting the per-period duopoly and triopoly profit, respectively. When there is no entry, we denote the incumbent's per-period monopoly profit by $\Pi^{M}$. These profits are assumed to satisfy the following standard conditions

\section{Assumption 1:}

(A) $\Pi^{M}>\Pi^{D}>\Pi^{T}$;

(B) $1 / 2 \Pi^{D}<\Pi^{T}<3 / 4 \Pi^{D}$.

Assumption A says more competition lowers profit per firm. Assumption B is more of technical nature and keeps probability of winning infringement suit between 0 and 1. Both assumptions are satisfied in Cournot oligopoly.

Let $\Delta$ denote the discounted sum of profit under triopoly; i.e., $\Delta=\Pi^{T} /(1-\delta)$. Assume that $\Delta-F>0$, meaning that entry is profitable for both generic firms when the patent expires. This makes analysis tractable, allowing the analysis to be focused on the central question of whether there is entry before the patent expires. If generic firms challenge the patent in the first two periods, the incumbent can either file patent infringement suit or accommodate entry. In case of the former choice, we assume that the FDA stays approval until litigation disputes are settled. As mentioned in the introduction, the two key features of litigation in our analysis are that it is time-consuming and uncertain. To capture the first feature, we assume that infringement litigation takes one period to be settled. ${ }^{8}$ This means that by filing suit the incumbent can delay generic entry for one period. To represent the second feature of litigation, we assume that the incumbent wins infringement suit

\footnotetext{
${ }^{8}$ If the incumbent takes two generic firms to a court at the same time, we assume that the probability that the incumbent wins the case is still $\alpha$. This occurs if the result that comes out first determines the one that comes out second. More on this, see Choi (1998).
} 
with positive probability $\alpha \in(0,1)$, which is common knowledge. ${ }^{9}$ To keep the analysis simple, we assume further that there are no court fees or litigation fees. Even in the absence of legal costs, litigation imposes time costs on the challengers, who must incur the entry cost $F$ for FDA approval and then wait for one period for a litigation outcome.

The incumbent may accommodate entry instead of filing infringement suit. In such a case, the FDA immediately grants approval to bring the generic drug products to the market immediately. However, the incumbent reserves the right to file infringement suit later so long as the patent is valid. In our model, it is possible that the incumbent accommodates the entrants in period 1 and sues them in period 2. Then, if the patent is found infringed, infringers are ordered to make compensations. In such case, we assume that infringers give the incumbent all the profits they earned while they were infringing the patent.

\subsection{The Counterfactual: Hatch-Waxman without market- ing exclusivity}

We begin with the counterfactual scenario: Hatch-Waxman without marketing exclusivity. This case serves as the benchmark for isolating the effect of marketing exclusivity. The game begins with two generic producers simultaneously deciding, in period 1, whether to challenge the patent of the incumbent's patent. Let $C$ denote the action challenge the patent and $\bar{C}$ the action do not challenge the patent. Their decisions give rise to three types of subgames, depending on the number of

\footnotetext{
${ }^{9}$ In reality the value of $\alpha$ may be relatively small since the enactment of Hatch-Waxman. According to a 2002 FTC study entitled Generic Drug entry Prior to Patent Expiration, generic applicants prevailed 73 per cent of the cases in which a court has resolved the patent dispute.
} 
challengers. Let $E_{00}$ denote a (symmetric) generic firm's discounted sum of profits if there are no challengers. If there is one challenger, the challenger's profit is denoted by $E_{10}$ and that of the non-challenger by $E_{01}$. If both firms challenge the patent, each receives the profit $E_{11}$. In the analysis to follow, we examine each subgame.

\subsubsection{Two challengers in period 1}

When both generic firms choose $\mathrm{C}$ in period 1, the incumbent sues them both immediately despite the positive probability of patent invalidation. To see this, observe that litigation yields the monopoly profit during period 1 because litigation is time-consuming. In period 2, a court delivers a decision, leading to monopoly (with probability $\alpha$ ) or triopoly (with probability $1-\alpha$ ). However, regardless of a court decision, there is triopoly from period 3 on. Thus, the incumbent's expected profit equals

$$
\Pi^{M}+\delta\left[\alpha \Pi^{M}+(1-\alpha) \Pi^{T}\right]+\delta^{2} \Delta .
$$

By contrast, accommodation yields $\Pi^{T}$ to the incumbent in period 1 . In period 2 , the incumbent again earns $\Pi^{T}$, whether it files suit or not, because the generic drugs are already in the market and its sales cannot be blocked by litigation. However, suing the entrants in period 2 dominates accommodating them once again because of the possible compensations the incumbent receives. Since the compensations amount to the sum of the profits earned by two generic firms in periods 1 and 2 , accommodating both firms in period 1 (and then suing them in period 2) yields

$$
\Pi^{T}(1+\delta)+\delta^{2} \Delta+2 \alpha \Pi^{T}(1+\delta)
$$

to the incumbent, where the third term represents the expected compensations. Since $\Pi^{M}>3 \Pi^{T}$, the profit is greater in (1.1) than in (1.2), and hence the conclusion: 
the incumbent always files suit against both challengers in period 1 . Therefore, the each challenger's equilibrium profit is

$$
E_{11}=-F+\delta(1-\alpha) \Pi^{T}+\delta^{2} \Delta
$$

The incumbent's profit is given in (1.1).

\subsubsection{One challenger in period 1}

When only one firm chooses $C$ in period 1 , filing suit guarantees the profit $\Pi^{M}$ in period 1 for the incumbent. In period 2, the incumbent earns $\Pi^{M}$ if the patent is valid. If the patent is found invalid, both generic firms enter, resulting in triopoly. Therefore, the incumbent's expected profit from suing the challenger in period 1 is the same as in $(1.1)$

$$
\Pi^{M}+\delta\left[\alpha \Pi^{M}+(1-\alpha) \Pi^{T}\right]+\delta^{2} \Delta .
$$

We show that filing infringement suit again dominates accommodation. Accommodation yields $\Pi^{D}$ to the incumbent in period 1 . In period 2 , if the other generic firm challenges the patent, suing both entrants firms stays FDA approval for the second challenger while allowing the marketing of the first generic. This yields the duopoly $\Pi^{D}$ again to the incumbent. In period 3, the patent has expired so there is triopoly, regardless of a court decision. However, if the patent is valid, the incumbent receives compensations from the first entrant, which amounts to its duopoly profits in periods 1 and 2. Thus, the incumbent's profit is

$$
(1+\delta) \Pi^{D}+\delta^{2} \Delta+\alpha \Pi^{D}(1+\delta)
$$

where the last term represents the compensations from the first generic firm. Since not suing in period 2 yields only $\Pi^{D}+\delta \Delta$, filing an infringement suit in period 
2 is the dominant strategy for the incumbent. Given this dominance, the second generic firm chooses not to enter in period 2 to avoid prepaying the entry cost $F$. Then, it is the dominant strategy for the incumbent to file suit against the firm it accommodated in period 1. A quick check shows that the incumbent's payoff is still equal to the one in (1.5).

Since $\Pi^{M}>2 \Pi^{D}$, the profit in (1.4) is greater than the one in (1.5), and hence the conclusion follows: the incumbent sues the first challenger in period 1 in equilibrium. The first challenger's equilibrium profit equals

$$
E_{10}=-F+\delta(1-\alpha) \Pi^{T}+\delta^{2} \Delta
$$

The non-challenger enters in period 2 only if the patent is found invalid; otherwise it waits till period 3 to enter. Hence its profit is

$$
E_{01}=\delta(1-\alpha)(\Delta-F)+\alpha \delta^{2}(\Delta-F)
$$

The incumbent's profit is given by (1.4).

\subsubsection{No challengers in period 1}

This case occurs if both firms choose $\bar{C}$. Then, the incumbent earns the monopoly profit in period 1 . In period 2 , generic firms again decide whether to challenge the patent or not. We show that if both challenge the patent, filing infringement suit again is the dominant strategy for the incumbent. Filing suit stays FDA approval for one period and yields the monopoly profit to the incumbent. In period 3, the patent expires, resulting in triopoly regardless of the court's decision. Thus, the incumbent's profit from filing suit is

$$
(1+\delta) \Pi^{M}+\delta^{2} \Delta
$$


In contrast, accommodating both firms in period 2 results in triopoly from then on, so the incumbent's profit is $\Pi^{M}+\delta \Pi^{T}+\delta^{2} \Delta$. Clearly, the incumbent sues generic firms in period 2, if both challenge the patent. The result is unchanged when there is only one challenger in period 2. The conclusion follows: the incumbent always files infringement suit in period 2, if it is challenged. Then, generic firms cannot make sales before period 3, and hence it is better to postpone entry till period 3 to avoid the entry cost prematurely. In a word, if there are no challengers in period 1, there are no challenges in period 2, either. Hence, each generic firm's expected profit (evaluated at period 1) equals

$$
E_{00}=\delta^{2}(\Delta-F)>0
$$

The incumbent's profit is given in (1.8).

\subsubsection{Equilibrium in period 1}

Having solved all the subgames, we are ready to turn to the first-stage game, where two generic firms simultaneously chooses an action from the set $\{C, \bar{C}\}$. This game is summarized in the table below, where the generic firms' payoffs $E_{i j}(i, j=1,0)$ are already defined above.

\begin{tabular}{c|c|c|}
\multicolumn{1}{c}{$c$} & \multicolumn{1}{c}{$\bar{c}$} \\
\cline { 2 - 3 }$c$ & $E_{11}, E_{11}$ & $E_{10}, E_{01}$ \\
\cline { 2 - 3 } $\bar{c}$ & $E_{01}, E_{10}$ & $E_{00}, E_{00}$ \\
\cline { 2 - 3 } & &
\end{tabular}

It is easy to show that $E_{11}<E_{01}$ thereby ruling out the simultaneous challenges. It is also verified that $E_{00}<E_{10}$ if and only if

$$
F>\Psi \equiv(1-\alpha) \delta \Pi^{T} /\left(1-\delta^{2}\right)
$$


Thus, if $F>\Psi$, the unique equilibrium has no challenging of the patent in periods 1 and 2. If $F \leq \Psi$, there are two pure Nash equilibria, in which only one firm challenges in period 1 . There is also the equilibrium in mixed strategies. ${ }^{10}$ However, this equilibrium is payoff-dominated by $(\bar{C}, \bar{C})$ for $\delta \geq(1-\alpha) /(2-\alpha)$. To keep the analysis simple, therefore, we focus on the pure-strategy Nash equilibrium. Then, we have:

Proposition 1.1 Suppose there is no marketing exclusivity in Hatch-Waxman.

(A) If $F \leq \Psi$, one generic firm challenges the patent in period 1 .

(B) If $F>\Psi$, there are no challenges before the patent expires, where

$$
\Psi \equiv(1-\alpha) \delta \Pi^{T} /\left(1-\delta^{2}\right)
$$

A challenge to the patent occurs if the entry cost is low enough in the sense that $F \leq \Psi$. Since a second generic firm enters only if the patent is invalid, it is concluded that two generic drugs are brought to the market in period 2 with probability $(1-\alpha)$.

Corollary 1.1 If $F \leq \Psi$, with probability $(1-\alpha)$ two generics are brought to the market in period 2. If $F \leq \Psi$, two generic drugs are available only after the patent expires.

Figure 1 illustrates proposition 1 . The line represents the relation $F=\Psi$. In the area on and below this line there is one generic challenger in period 1; above the line there are no challengers before the patent expires. Obviously, lower entry cost and/or higher likelihood (low $\alpha$ ) of patent invalidation entices a challenge to the patent.

\footnotetext{
${ }^{10}$ Each firm challenges the patent with probability $k=\left[\delta(1-\alpha) \Pi^{T}-F\left(1-\delta^{2}\right)\right] /[\delta(1-$ $\alpha)(1-\delta)(\Delta-F)]$. In this case, two firms enter with probability $k^{2}$.
} 


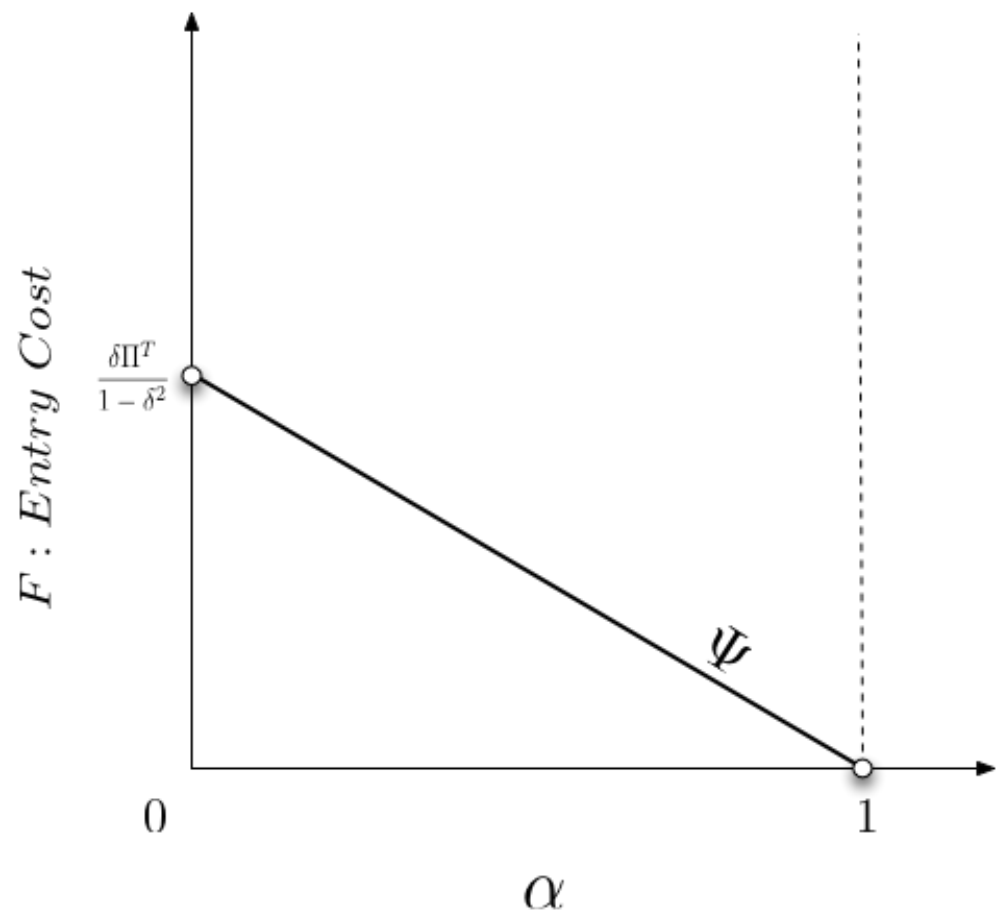

Figure 1.1: Equilibrium Without Marketing Exclusivity

We conclude this section with this remark. In the present model, only one firm challenges in period 1 because of the time-consuming litigation process. If litigation disputes are settled instantaneously as is usually assumed in the literature, there is a range of parameter values in which there are two challengers in period 1. Thus, the assumption of time-consuming litigation process is an important feature of our analysis.

\subsection{Marketing exclusivity}

In this section we examine how marketing exclusivity affects the generic firms' entry decisions. We assume that marketing exclusivity is granted to the first challenger 
of the patent for the length of one period. The analysis closely follows that of the previous section.

\subsubsection{Two challengers in period 1}

In this case, both generic firms incur the entry cost to challenge the patent in period 1. This case is similar to the corresponding case without marketing exclusivity, with the obvious difference: if the incumbent files infringement suit and loses, FDA approval is granted to only one of the challengers while FDA approval is stayed for the other firm. Then, the incumbent receives the following profit from suing both generic firms:

$$
\Pi^{M}+\delta\left[\alpha \Pi^{M}+(1-\alpha) \Pi^{D}\right]+\delta^{2} \Delta
$$

This profit is identical to the one in (1.4) in the preceding section, because with or without marketing exclusivity the incumbent faces one challenger.

In contrast, accommodation of both firms in period 1 leads to an immediate FDA approval, but only one generic is marketed in period 1. In period 2, marketing exclusivity expires, so the second generic is brought to the market. However, the patent has not expired yet so, the incumbent files infringement suit, which is its dominant strategy. To see this, note that the incumbent earns the triopoly profit in period 2, regardless of the litigation outcome, since both generics are in the market. As in the preceding section, the only motivation for infringement litigation is the compensations the incumbent can get from both generic firms. Thus, the incumbent earns the profit

$$
\Pi^{D}+\delta \Delta+\alpha\left(\Pi^{D}+2 \Pi^{T}\right)
$$

by filing suit in period 2, where the third term represents the (probability-weighted) compensations. In contrast, by accommodating the second challenger, the incum- 
bent forgoes the compensations, earning only $\Pi^{D}+\delta \Delta$, and hence the conclusion follows. Under Assumption 1, the profit in (1.10) exceeds the profit in (1.11), so the incumbent files infringement suit in period 1.

To calculate the generic firms' profits, we use the assumption that both generic firms believe each is granted marketing exclusivity with equal probabilities. ${ }^{11}$ Further, note that the FDA grants marketing exclusivity to one challenger and stays approval for the other. That means that when the marketing exclusivity expires the FDA approves the second generic without another review process; that is, the second generic firm can enter without incurring the entry cost $F$ again. Under these assumptions, each generic firm's expected profit is

$$
E_{11}=-F+\delta(1-\alpha)\left(\Pi^{D} / 2\right)+\delta^{2} \Delta
$$

The incumbent's equilibrium profit appears in (1.10).

\subsubsection{One challenge in period 1}

In this case by suing a single challenger in period 1 , the incumbent has the profit equal to the one in (1.10). The reason is that, as in the case of two challenges, the second generic firm waits till period 3 to enter because (A) if the incumbent wins the litigation, the second cannot challenge the patent in period 2 ; and (B) if the first generic firm wins the suit, exclusivity prevents entry in period 2.

Accommodation of a single challenger is slightly more complicated than when there are two challengers. In period 1, the challenger is accommodated and brings its generic product to the market, resulting in duopoly. In period 2, the market

\footnotetext{
${ }^{11}$ In reality, there are cases in which two generic firms file applications on the same day and end up sharing marketing exclusivity. This is a common strategy in the presence of numerous potential entrants. Given only two generic firms in our model, we disregard such a possibility.
} 
exclusivity expires but the patent does not. If the second generic firm challenges the patent in period 2 , the incumbent chooses to file suit. The reason is that litigation delays entry for one period, and with probability $\alpha$ the patent is upheld, allowing the incumbent to collect the compensations from the first generic firm. Therefore, the incumbent's expected profit equals

$$
\Pi^{D}(1+\delta)+\delta^{2} \Delta+\alpha \Pi^{D}(1+\delta)
$$

where the last term represents the expected compensations. In constant, accommodating the second generic firm in period 2 yields $\Pi^{T}+\delta \Delta$, which is clearly less than the profit in ((1.13). Thus, the incumbent sues the generic firms if the second firm challenges the patent in period 2. Even if there is no challenge from the second firm, the incumbent still sues the first entrant, because doing so yields the profit as in $\left((1.13)\right.$ while not suing yields $\Pi^{D}+\delta \Delta$, a smaller profit. Thus, the incumbent sues the first entrant in period 2, regardless of what the second firm does in period 2. Hence, the second generic firm's expected profit equals $-F+\delta \Delta$ from entry in period 2 and $\delta(\Delta-F)$ from non-entry. Clearly, the second firm waits till period 3 .

We have shown that, if it accommodates the first entrant in period 1, the incumbent sues that firm in period 2 and the second firm waits till period 3 . The incumbent's profit is equal to the one given in (1.13). Since this profit is smaller than the profit in ((1.10) obtained from suing the first challenger in period 1 , the incumbent always files infringement suit against the challenger in period 1 . Therefore, the challenge's equilibrium expected profit is

$$
E_{10}=-F+\delta(1-\alpha) \Pi^{D}+\delta^{2} \Delta,
$$

whereas the non-challenger's profit is given by

$$
E_{01}=\delta^{2}(\Delta-F)
$$

The incumbent's profit is given in ((1.11). 


\subsubsection{No challenges in period 1}

If there are no challengers in period 1 , the incumbent is a monopoly in period 1 . In period 2, two generic firms again simultaneously decide whether to challenge the patent or not. Since this case results in multiple subcases, requiring extensive but less illuminating examination, we relegate the analysis of this case to the two appendixes.

\subsubsection{Equilibrium in period 1}

Now we are ready to move back to period 1, where two generic firms play a simultaneous-move game. This part of the analysis is tedious, so we present it in Appendix B. The main conclusion from that appendix is the following proposition.

Proposition 1.2 Define $\Phi \equiv \delta(1-\alpha) \Pi^{D} /\left(1-\delta^{2}\right)$

(A) If $F \in(0, \Phi / 2)$, both generic firms challenge the patent in period 1 .

(B) If $F \in(\Phi / 2, \Phi)$, only one generic firm challenges the patent in period 1.

(C) If $F \in(\Phi, \infty)$, neither firm challenges the patent in period 1.

Figure 2 illustrates Proposition 2. Marketing exclusivity generates two critical borderline equations: $F=\Phi / 2$ (represented by the yellow line) and $F=\Phi$ (represented by the blue line). The area below the line $F=\Phi / 2$ has both firms challenge the patent in period 1 (although only one will be granted marketing exclusivity in period 2). Between the two lines there is only one generic firm that challenges the patent in period 1 . Above the line $F=\Phi$, thee are no challengers of the brand-name drug's patent in period 1 .

The next result is an immediate consequence of Proposition 2. 


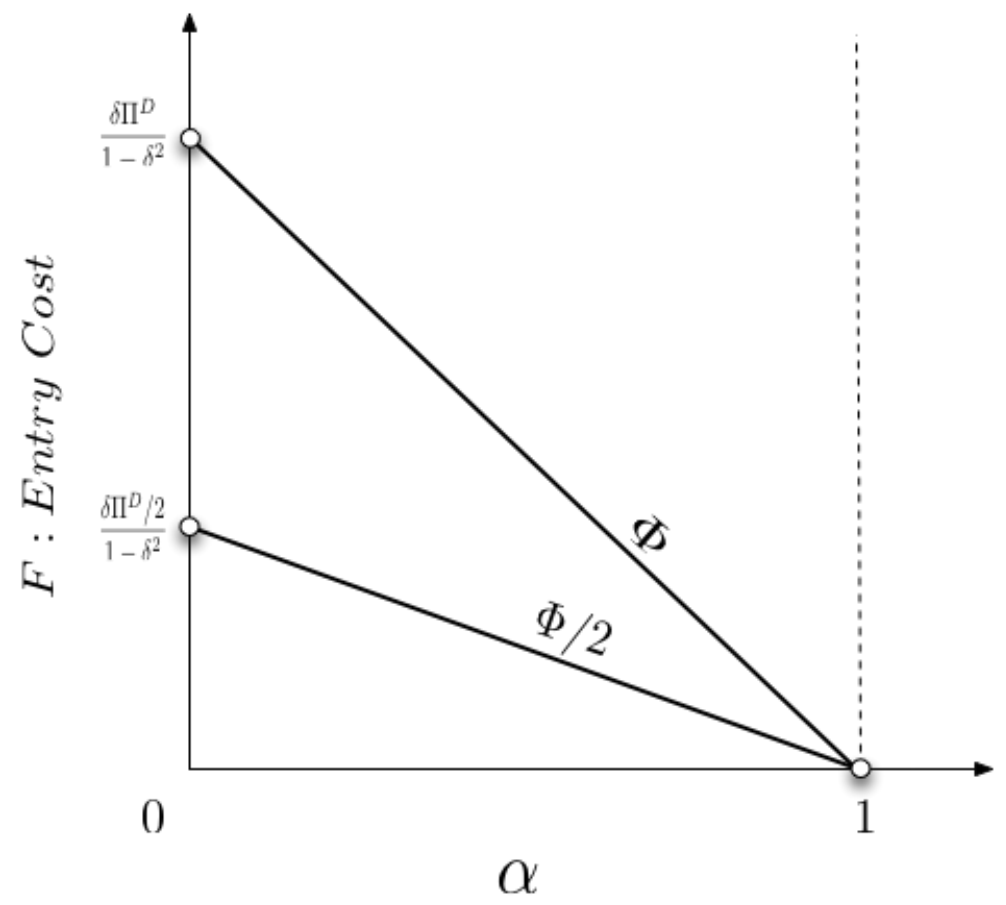

Figure 1.2: Equilibrium With Marketing Exclusivity

Corollary 1.2 If $F<\Phi$, with probability $(1-\alpha)$ there is one generic drug in period 2. If $F \geq \Phi$, there are no generics available before period 3.

\subsection{The effect of marketing exclusivity}

We are now ready to evaluate the effect of marketing exclusivity in Hatch-Waxman. To this end we refer to figure 3, which combines figures 1 and 2. By assumption 1, we have $\Phi / 2<\Psi<\Phi$, which explains the relative position of the three lines, which define four regimes, labeled by 1 through 4 . The regimes are ordered such that for a given $\alpha$ the entry cost is greater in a higher-numbered regime.

Regime 1: $F \leq \Phi / 2$ With marketing exclusivity, both generic firms challenge the patent in period 1 and the incumbent sues the entrants. If it successfully defends its 


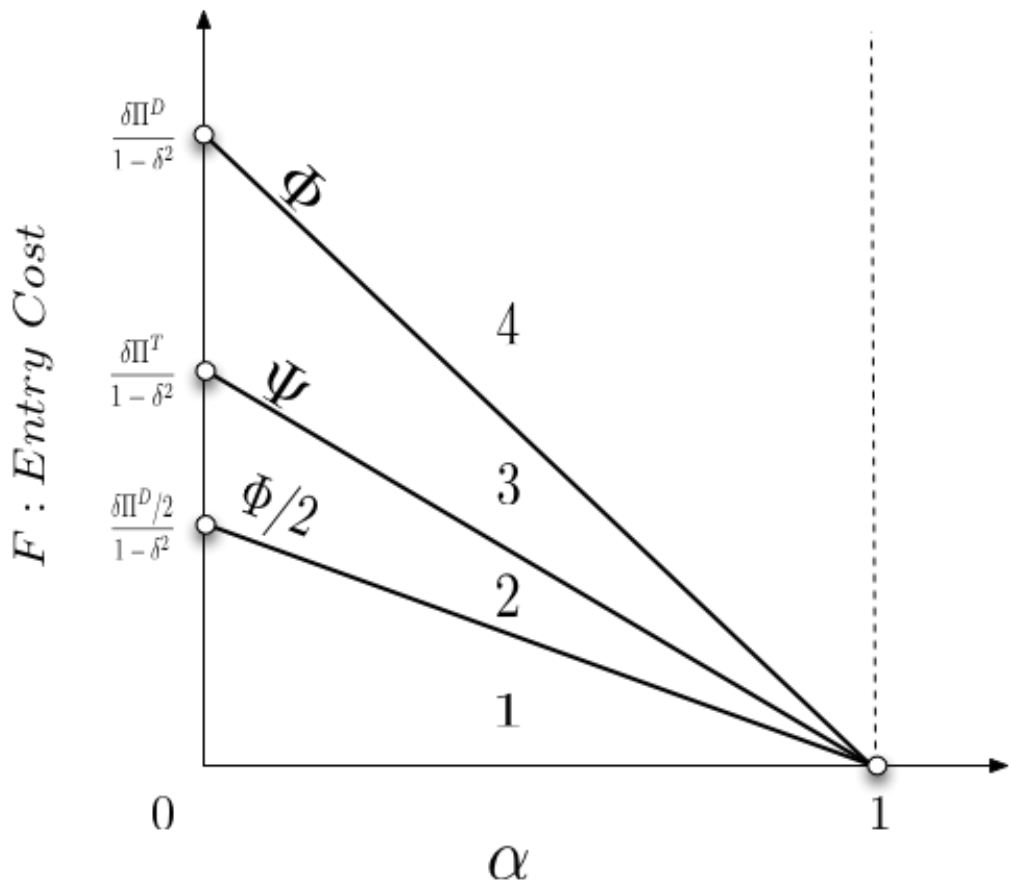

Figure 1.3: Equilibrium With/out Marketing Exclusivity: Comparisons

patent, the incumbent makes the monopoly profit in period 2; otherwise, it competes with the single generic company. Therefore, given that both firms are equally likely to be granted marketing exclusivity, each generic firm's expected profit is given by

$$
\delta(1-\alpha) \Pi^{D} / 2+\delta^{2} \Delta-F
$$

The incumbent's expected profit is given in (1.10), repeated here for a comparison:

$$
\Pi^{M}+\delta\left[\alpha \Pi^{M}+(1-\alpha) \Pi^{D}\right]+\delta^{2} \Delta .
$$

Without marketing exclusivity, only one generic challenges the patent in period 1. The other enters in period 2, only if the challenger is successful. Thus, each generic firm faces the expected profit

$$
\delta(1-\alpha) \Pi^{T}+\delta^{2} \Delta-\left[1+(1-\alpha) \delta+\alpha \delta^{2}\right](F / 2) .
$$


If the patent is found invalid, the incumbent competes with both generic firms in period 2; otherwise, it remains a monopoly. Therefore, the incumbent's equilibrium profit equals

$$
\Pi^{M}+\delta \alpha \Pi^{M}+\delta(1-\alpha) \Pi^{T}+\delta^{2} \Delta
$$

The profit in (1.15) is greater than the profit in (1.14) while the profit in (1.16) is less than the profit in (1.10).

Claim 1.1 In regime 1,

(A) there is one challenger without marketing exclusivity and two challengers with marketing exclusivity;

(B) market exclusivity increases the incumbent's expected profit and reduces the generic firm's expected profit.

Regime 2: $F \in(\Phi / 2, \Psi]$ With marketing exclusivity, there is only one generic challenge in period 1 . Hence, the equilibrium profit to the incumbent is the same as in regime 1 and is given in (1.16) above. As for the generic firm, we can show that a challenger's expected profit is $\delta(1-\alpha) \Pi^{D}-F+\delta^{2} \Delta$ while that of the non-challenger is $\delta^{2}(\Delta-F)$. Since both firms can be a challenger with equal likelihood, a generic firm's expected profit is given by

$$
\delta(1-\alpha) \Pi^{D} / 2+\delta^{2} \Delta-F\left(1-\delta^{2}\right) / 2
$$

Without marketing exclusivity, there is also only one challenge in period 1. Each generic firm's expected profit equals the profit in (1.14). The incumbent's equilibrium profit is given in (1.1), repeated below for a comparison

$$
\Pi^{M}+\delta\left[\alpha \Pi^{M}+(1-\alpha) \Pi^{T}\right]+\delta^{2} \Delta .
$$

Comparing the profits in (1.15) and (1.17) yields the first result of the next claim. Comparing the profits in (1.10) and (1.1) yields the second. 
Claim 1.2 In regime 2, where $F \in(\Phi / 2, \Psi]$ the following results hold:

(A) There is only one challenger with or without marketing exclusivity.

(B) Marketing exclusivity increases the incumbent's profit and

(C) Marketing exclusivity increases a generic firm's profit if $F>\left(2 \Pi^{T}-\Pi^{D}\right) /(1-$ $\delta)$ and decreases a generic firm's profit if the inequality is reversed.

For a given $F$, we are more likely to have $F>\left(2 \Pi^{T}-\Pi^{D}\right) /(1-\delta)$ when $\alpha$ is higher (when the patent is found valid with higher probability). In such cases marketing exclusivity increases all firms' expected profits.

Regime 3: $F \in(\Psi, \Phi]$ With marketing exclusivity, this regime leads to the same equilibrium outcome as regime 2, with (1.10) and (1.17) showing the equilibrium profits to the incumbent and each generic firm given, respectively. Regime 3 is distinct from regime 2, however, because without marketing exclusivity there are no challengers in regime 3. As both generic firms enter in period 3, their expected profit is $\delta^{2}(\Delta-F)$ and the incumbent's profit is $\Pi^{M}(1+\delta)+\delta^{2} \Delta$. Obviously, the incumbent makes a greater profit without marketing exclusivity in this regime. As for the generic firms, their profit in (1.17) exceeds $\delta^{2}(\Delta-F)$ if and only if $F \leq \Phi \equiv\left(\delta(1-\alpha) \Pi^{D}\right) /\left(1-\delta^{2}\right)$. This inequality is satisfied in regime 3 . Thus, we have proved the following result.

Claim 1.3 In regime 3, the following results hold:

(A) There is one challenger without marketing exclusivity and one challenger with marketing exclusivity.

(B) Marketing exclusivity reduces the incumbent's profit and increases a generic firm's profit. 
Regime 4: $F>\Phi$ With or without exclusivity, there are no challengers. In each scenario, the generic firm's expected profit equals $\delta^{2}(\Delta-F)$ and the incumbent's profit equals $\Pi^{M}(1+\delta)+\delta^{2} \Delta$. Thus,

Claim 1.4 In regime 4, there are no challengers with or without marketing exclusivity. Marketing exclusivity leaves unaffected the generic firms' and the incumbent's profits.

Claims 1- 4 leads to the next proposition:

Proposition 1.3 Claims 1- 4 leads to

(A) Marketing exclusivity increases the incumbent's expected profit when entry cost is low (regimes 1 and 2) but decreases its profit when entry cost is in the intermediate range (regime 3).

(B) Marketing exclusivity decreases a generic firm's expected profit when entry cost is sufficiently low (regimes 1 and 2) and increases its profit when entry cost is relatively high (regimes 2 and 3 ).

Claims 1 - 4 also yield the following observations. First, fix $F$ as shown by the horizontal broken line in figure 3. Then, without marketing exclusivity there is one challenger in period 1 for $\alpha \in\left[0, \alpha_{2}\right]$. With marketing exclusivity, there is at least one challenger for $\alpha \in\left[0, \alpha_{3}\right] \supset\left[0, \alpha_{2}\right]$. Thus, marketing exclusivity induces more generic firms to challenge the patent even though they are less likely to succeed (higher $\alpha$ ). In other words, marketing exclusivity induces generic firms to take greater risks. Next, fix the probability $\alpha$ as shown by the vertical broken line in figure 3. Without marketing exclusivity, there is one challenger for $F<F_{2}$ and there are no challenges for $F \geq F_{2}$. With marketing exclusivity, there are two challengers for $F<F_{1}<F_{2}$ (although only one generic is marketed in period 1 if challenges are 
successful), one challenger for $F \in\left[F_{1}, F_{2}\right)$, and no challenger for $F \geq F_{2}$. Thus, at a given $\alpha$, marketing exclusivity induces generic firms to challenge the patent at higher entry costs.

Suppose next that the entry cost is lowered sufficiently by the streamlined FDA review procedure for generic drugs as outlined in Section 2, and as a result we are in regime 1. There, with marketing exclusivity there are two challengers in period 1. If the incumbent loses the infringement suit, only one generic firm can market its generic product in period 2. By contrast, without marketing exclusivity, there is one challenger in period 1. However, if the incumbent loses the case, a second generic firm enters in period 2. Thus, marketing exclusivity tends to intensify entry competition between generic firms in period 1 but softens competition with the incumbent in period 2 .

The next result summarizes the above discussion.

\section{Proposition 1.4 Marketing exclusivity in Hatch-Waxman}

(A) induces generic firms to take greater risks, that is, challenge the patent even at higher probabilities of losing infringement suit,

(B) gives generic firms the incentive to challenge the patent even if they face higher entry costs, and

(C) intensifies entry competition between generic firms but softens competition against the incumbent.

We conclude this section with the following remark. As noted in the introduction, in Hatch-Waxman encourage generic firms to challenge the patent of the branded drug by reducing entry costs (through streamlining the FDA review process) and also by the granting of marketing exclusivity. This two-pronged approach, however, gives rise to the question of whether market exclusivity is redundant for inducing 
patent challenges. Suppose that initially $F$ is so high that $(\alpha, F)$ is above the line $F=\Psi$ in Figure 1, that is, there is no entry before the patent expires. The fact that there were hardly any patent challenges before Hatch-Waxman implies that we were likely to be in this case initially. Suppose that Hatch-Waxman lowers entry costs enough to put us in regime 1 or regime 2 ; that is, below the line $F=\Psi$. Then, without marketing exclusivity one generic firm challenges the patent in period 1 but in period 2 two generics become available with probability $(1-\alpha)$. In contrast, with marketing exclusivity, only one generic becomes available with the same probability. Therefore, marketing exclusivity is not only redundant in inducing the generic firms to challenge the patent but is harmful to consumers as it delays other generics' entry.

In short, marketing exclusivity impacts the incumbent, generic firms and consumers in a variety of ways, making the overall assessment of its effect unclear. In the next section we turn to this issue.

\subsection{The welfare effect of marketing exclusivity}

In this section we evaluate the welfare impact of market exclusivity. We adopt the standard definition of social surplus, which is the sum of consumer surplus and industry profit less entry costs. Denote the per-period consumer surplus under monopoly, duoply and trioply by $C S^{i}(i=M, D, T)$, respectively. Let $S^{i}$ denote the social surplus under the competition structures $i=M, D, T$. Assume that social surplus increases as the market becomes more competitive; i.e.,

$$
S^{M}\left(=\Pi^{M}+C S^{M}\right)<S^{D}\left(=2 \Pi^{D}+C S^{D}\right)<S^{T}\left(=3 \Pi^{T}+C S^{T}\right) .
$$

Define social welfare as the discounted sum of social surpluses evaluated at the beginning of period 1 . 


\subsubsection{Marketing exclusivity}

We first compute social welfare in the four regimes under marketing exclusivity.

Regime 1: In this regime there are two challengers in period 1 but the incumbent remains a monopoly as it files infringement suit. In period 2 there is duopoly with probability $(1-\alpha)$ and monopoly otherwise. There is triopoly in period 3. Thus, the social welfare is given by:

$$
\tilde{W}(1)=S^{M}-2 F+\alpha \delta S^{M}+(1-\alpha) \delta S^{D}+\delta^{2} S^{D} /(1-\delta)
$$

Regimes 2 and 3: In these regimes there is only one challenger in period 1 . In period 2, there is duopoly with probability $(1-\alpha)$ and monopoly, otherwise. In period 3 thee is triopoly. The social welfare is given by:

$$
\tilde{W}(2,3)=S^{M}-F+\alpha \delta S^{M}+(1-\alpha) \delta S^{D}+\delta^{2}\left[S^{D} /(1-\delta)-F\right] .
$$

Regime 4: There is no entry until period 3. Social welfare is given by

$$
\tilde{W}(4)=(1+\delta) S^{M}+\delta^{2}\left[S^{D} /(1-\delta)-2 F\right]
$$

\subsubsection{No marketing exclusivity}

We next compute the social welfare without marketing exclusivity. In regimes 1 and 2 , only one generic firm challenges in period 1 . In period 2 , if the patent is invalidated, there is triopoly, as the first generic firm markets its product, and the second also makes entry. Otherwise, there is monopoly until period 3, when the second firm enters. Social welfare is:

$$
\hat{W}(1,2)=S^{M}-F+\alpha \delta S^{M}+(1-\alpha) \delta S^{T}+\left(\delta^{2} S^{D}\right) /(1-\delta)-\delta F[(1-\alpha)+\alpha \delta] .
$$


In regimes 3 and 4 , there is no entry until period 3. The social welfare in these regimes is identical to in (1.20) above

$$
\hat{W}(3,4)=(1+\delta) S^{M}+\delta^{2}\left[S^{D} /(1-\delta)-2 F\right]=\tilde{W}(4)
$$

\subsubsection{The welfare impact of marketing exclusivity}

With the above calculations we can now make welfare comparisons.

Regime 1:

$$
\begin{aligned}
\tilde{W}(1)-\hat{W}(1,2) & =-F+(1-\alpha) \delta\left(S^{D}-S^{T}\right)-\delta F[(1-\alpha)-\alpha \delta] \\
& <F\left[(1-\alpha) \delta+\alpha \delta^{2}-1\right] \\
& =-(1-\delta)(1+\alpha \delta) F \\
& <0
\end{aligned}
$$

Therefore, in this regime marketing exclusivity decreases social welfare.

Regime 2:

$$
\begin{aligned}
\tilde{W}(2,3)-\hat{W}(1,2) & =(1-\alpha) \delta\left(S^{D}-S^{T}\right)-F\left[\delta^{2}-\delta(1-\alpha)-\alpha \delta^{2}\right] \\
& <-\delta(1-\delta)(1-\alpha) F \\
& <0
\end{aligned}
$$

Again, marketing exclusivity decreases social welfare.

Regime 3:

$$
\tilde{W}(2,3)-\hat{W}(3,4)=(1-\alpha) \delta\left(S^{D}-S^{M}\right)+\left(\delta^{2}-1\right) F
$$

The first term on the right is positive while the second is negative, so the impact of marketing exclusivity is ambiguous. To sign the difference, define $\bar{F}$ by

$$
\tilde{W}(2,3)-\hat{W}(3,4)=(1-\alpha) \delta\left(S^{D}-S^{M}\right)+\left(\delta^{2}-1\right) \bar{F}=0
$$


or

$$
\bar{F}=(1-\alpha) \delta\left(S^{D}-S^{M}\right) /\left(1-\delta^{2}\right)
$$

Then, $\tilde{W}(2,3)-\hat{W}(3,4)>0$ if and only if $F<\bar{F}$. Thus, marketing exclusivity increases social welfare if and only if $F<\bar{F}$. Since $\bar{F}$ depends on $\alpha$, we can use claim 3 above to derive

Claim 5: In regime 3:

(A) If $S^{D}-S^{M}<\Pi^{T}$, then $F>\bar{F}$ for all $\alpha$; i.e., marketing exclusivity decreases social welfare.

(B) If $S^{D}-S^{M}>\Pi^{D}$, then $F<\bar{F}$ for all $\alpha$; i.e., marketing exclusivity increases social welfare.

(C) If $\Pi^{T} \leq S^{D}-S^{M} \leq \Pi^{D}$, the effect on welfare is indeterminate.

Regime 4: By (1.20), $\hat{W}(3,4)=\tilde{W}(4)$ and hence marketing exclusivity has no effect on social welfare.

We summarize the main results of this section in

Proposition 1.5 Marketing exclusivity increases social welfare if and only if we are in regime 3, $i$. e., $F \in(\Psi, \Phi]$ and if $F<\bar{F}=(1-\alpha) \delta\left(S^{D}-S^{M}\right) /\left(1-\delta^{2}\right)$.

In general, both conditions on $\mathrm{F}$ are needed for the conclusion of proposition 6 to hold. In the case of Cournot competition with linear demand and constant marginal cost, regime 3 implies $F<\bar{F}$ and hence the second condition can be dispensed with.

\subsection{Concluding remarks}

Hatch-Waxman is intended to restore incentives for new drug development and simultaneously promote generic entry. To accomplish the first objective, it has 
extended patent length for new drugs; to accomplish the second, it has reduced entry costs and granted marketing exclusivity to a first generic firm that successfully challenges the patent. In this paper we find that marketing exclusivity suppresses competition among generics and harms consumers. Thus, removing the marketing exclusivity provision may improve social welfare, and benefit both consumers and generic firms. One caveat to this conclusion is that marketing exclusivity is also likely to raise the incumbent's profits and hence the incentive to develop new drugs. If this incentive-restoration effect is sufficiently strong, new drugs may be brought to the market sooner, thereby increasing social welfare in the long run. Exploring this possibility is left for future research.

Finally, our analysis also points out a new direction for empirical research. Currently, there is overwhelming evidence showing dramatic increases, since HatchWaxman, in the number of generics having been brought to markets before the branded drugs' patents expire. Our analysis raises the question as to what proportion of such increases is solely due to the streamlining of testing and application procedures and what proportion can be explained by marketing exclusivity alone. It is hoped that future research also addresses this important question. 


\section{CHAPTER 2}

\section{WHY AUTHORIZED GENERICS?: THEORETICAL AND EMPIRICAL INVESTIGATIONS}

\section{$2.1 \quad$ Introduction}

When facing generic competition, the brand-name companies sometimes launch generic versions of their own. Such generics, to be distinguished from ordinary (unauthorized) generics, are called authorized generics (AGs). Authorized generics contain exactly the same ingredients as the brand-name drugs and even come off the same production line, but are sold by a third party in the generic category.

Authorized generics directly compete with both regular generics and brand-name drugs. Since competition depresses the price of the brand-name drug, launching an authorized generic is a form of cannibalization for the brand-name company. This raises the question as to why the brand-name drug companies use such a strategy in the first place.

On the other hand, launching authorized drugs may make business sense if the brand-name drug company allows the authorized generic distributer to act as an autonomous entity but receives a large part of the latter's profit as side payments through contracts. This effect can be demonstrated with the standard model of Cournot oligopoly, in which a firm can always increase total profit by splitting itself into two autonomous entities. This idea is dubbed "divisionalization" by Baye et al. (1996). But if this is profitable the brand-name companies should always launch the AGs when facing generic competition. However, according to the AG list by the FDA (U. S. Food and Drug Administration), only a small number of off-patent brandname drugs have had AGs. This fact gives rise to another puzzle: if divisionalization 
is profitable, why don't brand-name drug companies launch authorized generics for all their off-the-patent drugs?

In this paper I attempt to address these puzzles. My investigation into the rationale for launch of authorized drugs begins by calling attention to yet another puzzle. Since generics (including authorized generics or AGs) are functionally the same as the brand-name drugs but priced lower, we would expect the prices of the brand-name drugs to fall swiftly to be more competitive when the generics become available in the market. However, we never see such precipitate price drops for brand-name drugs. Nor do we see huge demand shifts from the brand-name drug to the generics when the generics appear on the market. In this paper I explain these twin puzzles in terms of the customer bases the brand-name drugs build prior to generic entry. In economics jargon such customer bases can be analyzed using the notion of switching costs, popularized by a series of papers by Klemperer (Klemperer, 1987). What are the switching costs a consumer incurs when she switches from the brand-name drug to a generic? Drugs do not usually miraculously cure fatal illnesses. Rather, they only reduce the risk of death without entirely eliminating it by relieving symptoms of the illness such as pain or anxiety or by altering a clinical measurement - reduce cholesterol or blood pressure, for example. These effects are difficult to detect and evaluate even for scientists. In a word, drugs are essentially credence goods. As such, consumers tend to rely on personal experiences to gain confidence in the efficacy of the drug, and this confidence - and aversion to an alternative drug - grows if they use the drug repeatedly. In this respect, the brand-name drug has the first-mover advantage over generics simply because consumers have been using the brand-name drug before generics appear on the market. This acquired confidence in the brand-name drug serves as the switching cost - the benefit a consumer must give up when switching to generics. 
I now outline the present paper. I first present a two-period model of competition between a brand-name drug company and a generic firm. In the first period the brand-name company is a incumbent monopoly. In the second period a generic firm enters and two compete in quantities. The customers who buy the brand-name drug in the first period develop certain affinities to it as explained above and form a customer base for the incumbent in the second period. I assume that the brand-name company can influence the size of its customer base but cannot affect the switching cost per se. In other words, I treat the switching cost as a key parameter of this model. I then extend the analysis to allow the brand-name company to launch the authorized generic in period 2. I assume that a third party markets the authorized drug and all firms compete as Cournot oligopolists. I regard all three types of drugs (brand-name, generic and authorized generic) as homogeneous. The only thing that separates the brand-name drug from the other two in the second period is the presence of the switching costs. Thus, consumers who bought the brand-name drugs in the first period incur the same switching cost when they switch to either generic. Finally, it is assumed that the profit from AG sales is received by the brand-name company by contract (take-it-or-leave-it offer).

The analysis yields the following results. When the switching cost is relatively small, the incumbent is more likely to launch an authorized generic. In that case, it sells the brand-name drugs only to the customer base, and the authorized generic to new customers to compete with the regular generic. This has an intuitive explanation. In the standard Cournot game, launching of an AG only has the divisionalization effect, as shown by Baye et al. (1996). [6] In the presence of the customer base, by contrast, launching an AG also has the cannibalization effect, as it depresses the prices of the generic drugs and tempts some consumers in the customer base to switch. However, when the switching cost is sufficiently large, consumers do not 
switch easily so the incumbents prefer to distort the first-period output to create a larger customer base. Then the cannibalization is more damaging so it refrains from launching an AG and content itself with serving only the customer base. By contrast, when the switching cost is smaller, some consumer base erosion may occur, so creation of a large customer base is futile. But still it is preferable not to launch an AG so as to prevent further customer base erosions due to the cannibalization effect it creates. When the switching cost is even smaller, however, there is such substantial customer base erosion when the generic enters that the damage of cannibalization is minimal relative to the benefit from divisionalization. Thus, it is optimal for the incumbent to launch an AG when the switching cost is sufficiently small. Thus, the formal model yields a testable hypothesis as to a possible rationale for launching AGs. In the latter part of this paper, I test this hypothesis against the data collected from the FDA website and find strong support.

I now relate my work to the literature. Some papers examine the effects of authorized generics on non-authorized generic entry. For example, the FTC's 2009 report shows that the launch of AGs leads to low generic prices and revenues, and speculates that this may even lead to a collusive agreement between the generic and the brand-name firms and produce a double jeopardy for consumers: deferment of generic entry and non-marketing of AGs. ${ }^{1}$ Chen (2007) examines the legal issues arising from AGs, and calls for a legislative reform of the Hatch-Waxman Act. Reiffen and Ward (2005) shows that the launch of AGs reduces the number of potential generic entrants in the future. However, Berndt et al. (2007) concludes that, though AGs reduce the expected gains for generic patent challengers, sufficient

\begin{tabular}{lcccc}
\hline${ }^{1}$ Authorized & Generics: An Interim Report of the Fed- \\
eral Trade Commission, & 2009.
\end{tabular}


incentives remain for generic entry. Appelt (2010), examining the consequences of AG in Germany, also finds that the introduction of AGs has no effect on the number of generic entrants, and therefore is not for entry deterrence.

While all these papers focus on the effects of AGs on generic entry, little has been done as to the effects of AG launch on the brand-name companies. My paper is an attempt to fill this lacuna in the literature. My findings are consistent with recent empirical findings. For example, my first finding that brand-name companies launch AGs when switching costs are low receives indirect support from Appelt (2010) who identifies earning generic profits as the primary motive for introduction of AGs. My result may also explain the empirical finding of Berndt et al. (2007) that drugs with higher pre-generic revenues are more likely to have AGs. My analysis shows that for a given switching cost, the incumbent is more likely to launch an AG if the market is larger. The in- tuition is that an increase in demand (intercept) expands the divisionalization effect relative to the cannibalization effect (more specifically, it raises the sum of the combined profit from brand-name drug and AG sales by a greater magnitude than the profit from brand-name drug sales alone). If the pre-generic revenues are interpreted as a proxy of the market size, my finding is consistent with that of these authors.

The remainder of this chapter is organized in 5 sections. In section 2 I present a two-period model of Cournot oligopoly. In this version, the incumbent builds a customer base in the first period but does not launch an AG when there is generic entry in the second period. In section 3 I extend the model so as to allow the incumbent to market an $\mathrm{AG}$ through a third party. In section $4 \mathrm{I}$ compare the incumbent's profits between the two scenarios described above and show that the launch of an AG is profitable to the incumbent only when the switching cost is 
relatively small. In section 5 I present an empirical model to test the hypothesis and discuss my empirical findings. Section 6 concludes the paper.

\subsection{Competitions Without AG}

This section presents a two-period model of entry and competition without AG. The model has the following game structure. In period 1, a brand-name company, an incumbent monopoly, chooses quantity $B$. I suppose that each consumer buys one unit of a drug, so $B$ represents the number of the customers who buy the branded drug in period 1. Those customers develop affinities towards the brand-name drug and constitute its customer base. These affinities they acquire define the switching cost of this model, which we denote by s. In period 2, a generic firm enters and two firms play a Cournot game. I assume that all drugs are produced at common constant marginal cost, which I set equal zero to simplify the exposition. I assume for tractability that the demand function is linear and is given by $p=m-Q$, where $\mathrm{m}$ is demand intercept and $Q$ is total supply. I then solve the model for the subgame-perfect Nash equilibrium.

Let me begin with the second period, where the customer base $B$ is given. Let $b$ and $g$, respectively, denote the quantity of output supplied by the incumbent and the generic firm in period 2 so that $Q=b+g$. The entrant maximizes the profit $\Pi_{g}=(m-b-g) g$, yielding the standard best-response function $g(b)=(m-b) / 2$. To derive the incumbent's best-response function, note that the incumbent faces the inverse demand function:

$$
p_{2}(b)= \begin{cases}m+s-b-g & \text { if } b \leq B \\ m-b-g & \text { if } b>B\end{cases}
$$


which is discontinuous at output $b=B$. Therefore, the incumbent's profit is discontinuous at $b=B$ and given by

$$
\pi_{b}= \begin{cases}(m+s-b-g) b & \text { if } b<B \\ (m+s-B-g) B & \text { if } b=B \\ (m-b-g) b & \text { if } b>B\end{cases}
$$

In Figure 1, the curve to the left of $B$ (solid line) displays the profit

$$
\pi(b, s, g)=(m+s-b-g) b,
$$

while the one to the right of $\mathrm{B}$ (solid line) corresponds to the function

$$
\pi(b, g)=(m-b-g) b
$$

Now, to obtain the incumbent's best-response function, define these key quantities: $\bar{b}(g)=\arg \max (m+s-b-g) b$ and $\underline{b}(g)=\arg \max (m-b-g) b$. Write the corresponding maximum profits as $\bar{\pi}(\bar{b}, s, g)$ and $\underline{\pi}(\underline{b}, g)$. Define next the quantity $\hat{b}(g)$ implicitly by $\pi(\hat{b}, s, g)=(m+s-\hat{b}-g)=\underline{\pi}(\underline{b}, g)$. Then, it is obvious that for given $g$

$$
\hat{b}(g)<\underline{b}(g)<\bar{b}(g)
$$

In the linear case we have,

$$
\begin{aligned}
& \bar{b}(g)=(m+s-g) / 2 \\
& \underline{b}(g)=(m-g) / 2 \\
& \hat{b}(g)=(m+s-g-\sqrt{s(2 m+s-2 g)}) / 2
\end{aligned}
$$

Now, as $g$ increases, the profit functions $\pi(b, s)$ and $\pi(b)$ shift down, giving rise to the following three cases, depending on $B$. 
(i) $g$ is relatively small such that $B \leq \hat{b}(g)$. Then the incumbent's best response is $\underline{b}(g)$

(ii) $g$ takes on an intermediate value so that $\hat{b}(g)<B<\bar{b}(g)$. In this range the incumbent's best response is $B$.

(iii) $g$ is large so that $\bar{b}(g) \leq B$. In this case its best response is $\bar{b}(g)$.

These three cases are displayed in Figures $1-3$.

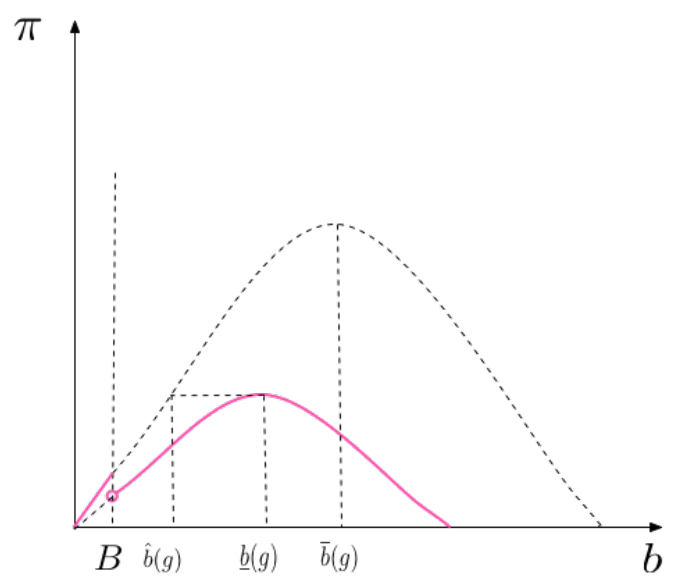

Figure 2.1: $g$ is relatively small so that $B \leq \hat{b}(g)$

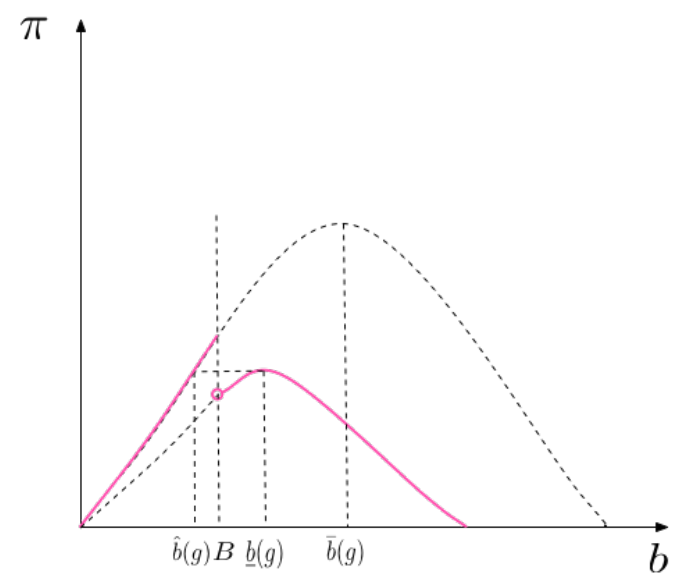

Figure 2.2: $g$ is intermediate so that $\hat{b}(g)<B<\bar{b}(g)$ 


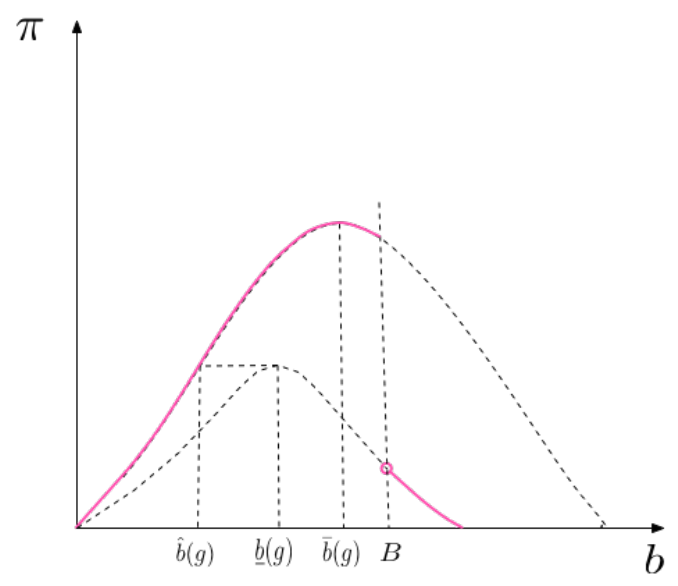

Figure 2.3: $g$ is large so that $\bar{b}(g) \leq B$

The incumbent's best-response function thus comprises three segments as shown in figure 4 , with the discontinuity at $b=B$. This result holds as long as each firm's profit function is strictly concave in its own quantity. Accordingly, the incumbent's best-respond function is given by

$$
b(g)= \begin{cases}(m-g) / 2 & \text { if } g \leq m-2 B-2 \sqrt{s B} \\ B & \text { if } g \in(m-2 B-2 \sqrt{s B}, m-2 B+s) \\ (m+s-g) / 2 & \text { if } g \geq m-2 B+s\end{cases}
$$

In period 1 the incumbent can choose $B$ to affect the intersection of the two best-response functions in period 2 .

(a) Suppose that $B$ is such that the intersection occurs on the segment of the incumbent's best-response function given by $b(g)=(m-g) / 2$. We then compute the range of $B$ that leads to this outcome. ${ }^{2}$ Combining with $g(b)=$

${ }^{2}$ Calculations show that if

$$
B \in\left[\left(3 m+8 s-4 \sqrt{s^{2}+3 m s}\right) / 9,\left(2 m+3 s-\sqrt{9 s^{2}+12 m s}\right) / 6\right]
$$

there will be two intersections, one on the $b(g)=(m-g) / 2$ segment, the other one on the $b(g)=B$ segment. However, the latter always yields the incumbent a higher profit, and 


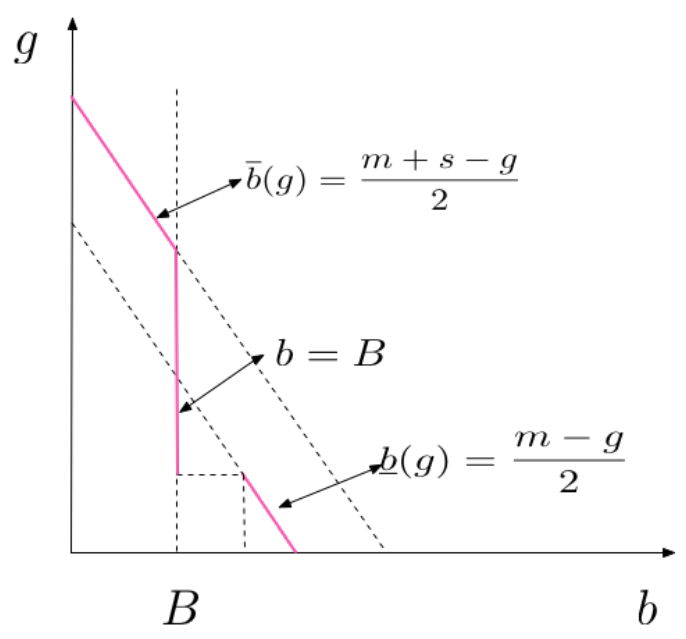

Figure 2.4: The incumbent's best-response function

$(a-b) / 2$, we have $b=g=m / 3$. To satisfy the constraint $g \leq m-2 B-2 \sqrt{s B}$ given above, we must have $m / 3 \leq m-2 B-2 \sqrt{s B}$. This condition simplifies to $^{3}$

$$
B \leq\left(2 m+3 s-\sqrt{9 s^{2}+12 m s}\right) / 6 .
$$

(b) Suppose that the intersection is on the segment $b(g)=(m+s-g) / 2$ of the incumbent's best response function. The corresponding Cournot outputs are $b=(m+2 s) / 3$ and $g=(m-s) / 3$ To satisfy the condition $g \geq m-2 B+s$, we must have $(m-s) / 3 \geq m-2 B+s$ or $^{4}$

$$
B \geq(m+2 s) / 3
$$

hence we assume that the incumbent always picks the one on the $(m-g) / 2$ segment.

${ }^{3} B$ also has to satisfy the condition that $B \leq b=m / 3$.

${ }^{4} B$ also has to satisfy the condition that $B \geq b=(m+2 s) / 3$. 
(c) Suppose finally that the intersection occurs on the vertical segment of the incumbent's best-response function, i. e., $g(b)=B$ Then,

$$
B \in\left(\left(2 m+3 s-\sqrt{9 s^{2}+12 m s}\right) / 6,(m+2 s) / 3\right) .
$$

If we let

$$
\hat{B}=\left(2 m+3 s-\sqrt{9 s^{2}+12 m s}\right) / 6,
$$

we can write the incumbent's equilibrium second-period profit as

$$
\pi_{b}= \begin{cases}m^{2} / 9 & \text { if } B \in(0, \hat{B}] \\ (m-B+2 s) B / 2 & \text { if } B \in(\hat{B},(m+2 s) / 3) \\ (m+2 s)^{2} / 9 & \text { if } B \in[(m+2 s) / 3, \infty)\end{cases}
$$

We are now in a position to move to period 1 . In that period the incumbent chooses its output $B$ to maximize the sum of profits in both periods (we ignore discounting), which are written as

$$
\Pi_{b}= \begin{cases}(m-B) B+m^{2} / 9 & \text { if } B \in(0, \hat{B}] \\ (m-B) B+(m-B+2 s) B / 2 & \text { if } B \in(\hat{B},(m+2 s) / 3) \\ (m-B) B+(m+2 s)^{2} / 9 & \text { if } B \in[(m+2 s) / 3, \infty)\end{cases}
$$

2.2.1 $B \in[0, \hat{B}]$

The incumbent's total profit is:

$$
\Pi=(m-B) B+m^{2} / 9 .
$$

In this case, $B$ has no effect on the incumbent's period 2 profits. Thus, $\Pi$ is maximized at $B=m / 2$. However, since $m / 2>\hat{B}$, the constraint on $B$ is binding. Therefore, the optimal $B$ is $\hat{B}$, and the maximum profit will be $\Pi(\hat{B})$. 
2.2.2 $B \in(\hat{B},(m+2 s) / 3)$

The incumbent's total profit is:

$$
\Pi=B(m-B)+(m-B+2 s) B / 2 .
$$

The unconstrained optimum occurs at $B=(3 m+2 s) / 6$, which is greater than $\hat{B}$. Comparing $(3 m+2 s) / 6$ with $(m+2 s) / 3$, I find:

$$
\begin{cases}(m+2 s) / 3>(3 m+2 s) / 6 & \text { if } s>m / 2 \\ (m+2 s) / 3 \leq(3 m+2 s) / 6 & \text { if } s \leq m / 2\end{cases}
$$

Therefore, when $s>m / 2, B=(3 m+2 s) / 6$ is within this feasible range of $B$, and the maximum profit is denoted by $\Pi((3 m+2 s) / 6)$. When $s \leq m / 2, B=(3 m+2 s) / 6$ exceeds the upper limit of the range of $B$. Therefore, there is no optimal $B$ in this range, but there is the supremum $B=(3 m+2 s) / 6$.

\subsection{3 $B \in[(m+2 s) / 3, \infty)$}

The incumbent's total profit is

$$
\Pi=B(m-B)+(m+2 s)^{2} / 9
$$

The unconstrained optimum occurs at $B=m / 2$. Comparing $m / 2$ with $(m+2 s) / 3$, I find that:

$$
\begin{cases}m / 2 \geq(m+2 s) / 3 & \text { if } s \leq m / 4 \\ m / 2<(m+2 s) / 3 & \text { if } s>m / 4\end{cases}
$$

Therefore, when $s \leq m / 4$, the maximum profit is $\Pi(m / 2)=m^{2} / 4+(m+2 s)^{2} / 9$. When $s>m / 4$, the maximum profit is $\Pi((m+2 s) / 3)=[2(m+2 s)(m-s)+(m+$ $\left.2 s)^{2}\right] / 9$. 


\subsubsection{Global maxima without AG}

So far we identified the local maxima. We now turn to the global maxima for the incumbent.

When $s \leq m / 4$, the incumbent can choose $B \in(0, \hat{B}]$ or $B \in[(m+2 s) / 3, \infty)$ and receive the corresponding profits $\Pi(\hat{B})$ and $\Pi(m / 2)$. Computation shows that $\Pi(\hat{B})<\Pi(m / 2)$ so the global optimum occurs at $B=m / 2$ and $b=(m+2 s) / 3$. The incumbent's equilibrium total profit is $\Pi(m / 2)$.

When $s \in(m / 4, m / 2]$, the incumbent chooses $B \in(0, \hat{B}]$ or $B \in[(m+2 s) / 3, \infty)$ and obtains the local maximum $\Pi(\hat{B})$ and $\Pi((m+2 s) / 3)$. A calculation establishes that $\Pi(\hat{B})<\Pi((m+2 s) / 3)$ so the global maximum occurs at $B=(m+2 s) / 3$ and $b=(m+2 s) / 3$. The equilibrium total profit is $\Pi((m+2 s) / 3)$.

When $s \in(m / 2, m)$, the incumbent chooses $B \in(0, \hat{B}]$ or $B \in(\hat{B},(m+2 s) / 3)$ or $B \in[(m+2 s) / 3, \infty)$ and achieves the corresponding local maxima: $\Pi(\hat{B}), \Pi((3 m+$ $2 s) / 6)$ and $\Pi((m+2 s) / 3)$. Computation shows that $\Pi((3 m+2 s) / 6)$ exceeds the other two. Hence, the equilibrium outputs are $B=(3 m+2 s) / 6$ and $b=(3 m+2 s) / 6$, and its total profit is $\Pi((3 m+2 s) / 6)$.

These results are summarized in

Proposition 2.1 The equilibrium customer base is given by

$$
B= \begin{cases}m / 2 & \text { if } s \in(0, m / 4], \\ (m+2 s) / 3 & \text { if } s \in(m / 4, m / 2], \\ (3 m+2 s) / 6 & \text { if } s \in(m / 2, m) .\end{cases}
$$

The following results are immediate consequences of Proposition 2.1

Proposition 2.2 A) When $s \in(0, m / 4]$, the brand-name firm sells less than its customer base in the second period; B) When $s \in(m / 4, m)$, the brand-name firm holds on to its customer base in the second period. 
From Proposition 2.2, we can see that the brand-name drug is never sold to new customers in the second period. This implies that those who bought the brand-name drug in the first period are willing to pay the premium over the generic, which is the switching cost. This finding explains why, in the real world, the brand-name drugs are always priced higher than their generic counterparts.

\subsection{With AG}

In this section we allow the incumbent to introduce an AG through a third party in period 2. The firm distributing the AG is autonomous and competes fully with the brand-name drug company and the generic firm. However, we assume that the incumbent makes a take-it-or-leave-it offer to the management of the AG firm so that that it can collect the profit from AG sales through a contractual agreement with the AG supplier.

The model is similar to the one developed in the preceding section. In the first period the incumbent chooses the quantity $B$. In the second period, it competes with two generic firms. Let a denote the quantity of the authorized generic supplied, and $\mathrm{b}$ and $\mathrm{g}$ the quantities of the brand-name drug and the generic drug supplied in the second period. With this notation the brand-name company faces the inverse demand function:

$$
p_{2}= \begin{cases}m+s-b-a-g & \text { if } b \leq B \\ m-b-a-g & \text { if } b>B\end{cases}
$$


Note that the demand function is discontinuous at output $b=B$. Therefore, the incumbent's profit is also discontinuous at $b=B$ :

$$
\pi_{b}= \begin{cases}(m+s-b-a-g) b & \text { if } b<B \\ (m+s-B-a-g) B & \text { if } b=B \\ (m-b-a-g) b & \text { if } b>B\end{cases}
$$

The incumbent's best response function can be written as

$$
b(a, g)= \begin{cases}(m-a-g) / 2 & \text { if } a+g \leq m-2 B-2 \sqrt{s B} ; \\ B & \text { if } a+g \in(m-2 B-2 \sqrt{s B}, m-2 B+s) \\ (m+s-a-g) / 2 & \text { if } a+g \geq m-2 B+s .\end{cases}
$$

Without the customer base, the generic faces the demand $p_{2}=m-b-a-g$ and the profit $\pi_{g}=(m-b-a-g) g$. The generic firm maximizes it profit $\pi_{g}$. Its best response function is given by

$$
g(b, a)=(m-b-a) / 2 .
$$

Similarly, the authorized generic faces the same demand $p_{2}=m-b-a-g$ and the profit $\pi_{a}=(m-b-a-g) a$. The authorized generic distributor maximizes its profit $\pi_{a}$. Its best response is given by

$$
a(b, g)=(m-b-g) / 2 .
$$

Then, depending on $B$, the incumbent can adjust the shape of its best response function so that it can reach the equilibrium either at its lower segment $(b=(m-$ $a-g) / 2)$, middle segment $(b=B)$ or upper segment $(b=(m+s-a-g) / 2)$. According to different ranges of $B$, the incumbent's equilibrium profits (including 
the profit of $\mathrm{AG}$ ) are:

$$
\pi_{b}= \begin{cases}m^{2} / 16 & \text { if } B \in(0, \tilde{B}] ; \\ B(m-B+3 s) / 3 & \text { if } B \in(\tilde{B},(m+3 s) / 4) ; \\ (m+3 s)^{2} / 16 & \text { if } B \in[(m+3 s) / 4, \infty) .\end{cases}
$$

where $\tilde{B}=(\sqrt{m+s}-\sqrt{s})^{2} / 4$. The AG makes equilibrium profits:

$$
\pi_{a}= \begin{cases}m^{2} / 16 & \text { if } B \in(0, \tilde{B}] \\ \left.B(m-B)^{2}\right) / 9 & \text { if } B \in(\tilde{B},(m+3 s) / 4) \\ (m-s)^{2} / 16 & \text { if } B \in[(m+3 s) / 4, \infty) .\end{cases}
$$

In the first period, the brand-name firm's profit is $(m-B) B$, so the incumbent's total profits are :

$\Pi_{A G}= \begin{cases}(m-B) B+m^{2} / 8 & \text { if } B \in(0, \tilde{B}] ; \\ (m-B) B+B(m-B+3 s) / 3+\left(B(m-B)^{2}\right) / 9 & \text { if } B \in(\tilde{B},(m+3 s) / 4) ; \\ (m-B) B+(m+3 s)^{2} / 16+(m-s)^{2} / 16 & \text { if } B \in[(m+3 s) / 4, \infty) .\end{cases}$

\subsection{1 $B \in(0, \tilde{B}]$}

In the first period, the incumbent chooses $B$ to maximize its total profit

$$
\Pi_{A G}=B(m-B)+m^{2} / 8 .
$$

In this case, $B$ has no effect on the incumbent's period 2 profits. Thus, $\Pi_{A G}$ is maximized at $B=m / 2$. However, since $m / 2>\tilde{B}$, the constraint on $\mathrm{B}$ is binding. Therefore, the optimal $B$ is $\tilde{B}$, and the maximum profit will be $\Pi_{A G}(\tilde{B})$. 
2.3.2 $B \in(\tilde{B},(m+3 s) / 4)$

In the first period, the incumbent chooses B to maximize its total profit

$$
\Pi_{A G}=B(m-B)+B(m-B+3 s) / 3+(m-B)^{2} / 9 .
$$

The unconstrained optimum is reached at $B=(10 m+9 s) / 22$. However, when $s \leq 3 m / 5$, this exceeds the upper bound of the interval for this case and hence there is no optimum. , The supremum exists and equals $B=(m+3 s) / 4$. On the other hand, when $s>3 m / 5,(10 m+9 s) / 22<(m+3 s) / 4$, and hence the incumbent chooses $B=(10 m+9 s) / 22$ and reaches the maximum profit

$$
\begin{aligned}
\Pi_{A G}((10 m+9 s) / 22)= & (10 m+9 s) / 22(m-(10 m+9 s) / 22) \\
& +(10 m+9 s) / 66(m+3 s-(10 m+9 s) / 22) \\
& +1 / 9(m-(10 m+9 s) / 22)^{2} .
\end{aligned}
$$

\subsection{3 $B \in[(m+3 s) / 4, \infty)$}

In the first period, the incumbent chooses $B$ to maximize its total profit

$$
\Pi_{A G}=B(m-B)+(m-s)^{2} / 16+(m+3 s)^{2} / 16
$$

The unconstrained optimum is at $B=m / 2$. We have

$$
\begin{cases}m / 2 \geq(m+3 s) / 4 & \text { if } s \leq m / 3 \\ m / 2<(m+3 s) / 4) & \text { if } s>m / 3\end{cases}
$$

Hence, when $s \leq m / 3$, the incumbent chooses $m / 2$ and earns the maximum profit

$$
\Pi_{A G}(m / 2)=m^{2} / 4+(m-s)^{2} / 16+(m+3 s)^{2} / 16
$$

otherwise, the incumbent chooses $(m+3 s) / 4$, and receives the maximum profit

$$
\Pi_{A G}((m+3 s) / 4)=(m+3 s) / 4(m-(m+3 s) / 4)+(m-s)^{2} / 16+(m+3 s)^{2} / 16
$$




\subsubsection{Global Maxima with AG}

The incumbent selects $B$ to maximize its total profit in two periods. Depending on $s$, it can achieve local maximum profit within different ranges of $B$. Comparing these local maxima, we can find the global maximum profit and therefore the globally optimal first period output $B$.

When $s \leq m / 3$, the incumbent can choose $B \in(0, \tilde{B}]$ or $B \in[(m+3 s) / 4, \infty)$ and receive the corresponding profits $\Pi_{A G}(\tilde{B})$ and $\Pi_{A G}(m / 2)$. Computation shows that $\Pi_{A G}(\tilde{B})<\Pi_{A G}(m / 2)$, so the global optimum occurs at $B=m / 2$ and $b=(m+3 s) / 3$. The incumbent's equilibrium total profit is $\Pi_{A G}(m / 2)$.

When $s \in(m / 3,3 m / 5]$, the incumbent chooses $B \in(0, \tilde{B}]$ or $B \in[(m+3 s) / 4, \infty)$ and obtains the local maximum $\Pi_{A G}(\tilde{B})$ and $\Pi_{A G}((m+3 s) / 4)$. A calculation shows that $\Pi_{A G}(\tilde{B})<\Pi_{A G}((m+3 s) / 4)$ so the global maximum occurs at $B=(m+3 s) / 4$ and $b=(m+3 s) / 4$. The equilibrium total profit is $\Pi_{A G}((m+3 s) / 4)$.

When $s \in(3 m / 5, m)$, the incumbent chooses $B \in(0, \tilde{B}]$ or $B \in(\tilde{B},(m+3 s) / 4)$ or $B \in[(m+3 s) / 4, \infty)$ and achieves the corresponding local maxima: $\Pi_{A G}(\tilde{B})$, $\Pi_{A G}((10 m+9 s) / 22)$, and $\Pi_{A G}((m+3 s) / 4)$. Computation shows that $\Pi_{A G}((10 m+$ $9 s) / 22)$ exceeds the other two. Hence, the equilibrium outputs are $B=(10 m+$ $9 s) / 22$ and $b=(10 m+9 s) / 22$, and its total profit is $\Pi_{A G}((10 m+9 s) / 22)$.

Proposition 2.3 With $A G$, the equilibrium customer base is given by

$$
B= \begin{cases}m / 2 & \text { if } s \in(0, m / 3] ; \\ (m+3 s) / 4 & \text { if } s \in(m / 3,3 m / 5] ; \\ (10 m+9 s) / 22 & \text { if } s \in(3 m / 5, m) .\end{cases}
$$




\subsection{Comparisons}

In this section we compare the incumbent's profit in two regimes at various values of $s$.

First, for $s \in(0, m / 4]$, the incumbent's profit is $\Pi(m / 2)$ without $A G$ and $\Pi_{A G}(m / 2)$ with AG. Calculations show that when $s \in(0,0.077 m), \Pi(m / 2)<$ $\Pi_{A G}(m / 2)$, meaning that launching an AG will be more profitable for the incumbent; when $s \in[0.077 m, m / 4], \Pi(m / 2) \geq \Pi_{A G}(m / 2)$, meaning that the launch of a AG is less profitable.

When $s \in(m / 4, m / 3]$, the incumbent's profits are $\Pi((m+2 s) / 3)$ without AG, and $\Pi_{A G}(m / 2)$ with AG. It can be shown that $\Pi((m+2 s) / 3)$ is the greater of the two; hence the incumbent will not launch AG if the switching cost is within this range. In all other values of s calculations show that the incumbent receives greater profits by not launching an AG. We thus conclude that the incumbent launches an AG only when the switching cost is sufficiently small, namely, if $s<0.077 m$.

Proposition 2.4 The incumbent launches an $A G$ only when s; $0.077 \mathrm{~m}$.

This result contrasts sharply with the standard result from Cournot oligopoly. In the standard Cournot model an oligopolist can increase total profits by setting up another company that competes with the parent company providing that starting such a company is costless; see Baye et al. (1996). This fact also lies at the heart of the so-called horizontal merger puzzle first formulated by Salant et al. (1983).

Proposition 2.4 leads to the following empirically testable hypothesis.

Hypothesis 1 The brand-name company is more likely to launch the AG when the switching cost is relatively low.

In the next section we test this hypothesis. 


\subsection{Empirical investigations}

\subsubsection{Data}

In this section we empirically test the hypotheses presented at the end of the preceding section. To that end, I use the dataset I collected on all the brand-name drugs that have experienced generic penetration from the beginning of 2001 till the beginning of 2003 .

This data set was constructed by combining information from three different resources on the FDA website. The first resource is the First Generics list. ${ }^{5}$ First Generics are "those drug products that have never been approved before as generic drug products and are new generic products to the marketplace". From this list, I obtained the information about all the first generics approved from 2001 to 2003, including the generic names and the dates that they were approved for marketing. Then I used the name of the generics to find out the corresponding brand-name drugs in the Orange Book. ${ }^{6}$ The Orange Book lists all the brand-name drugs and their generic counterparts, including the names, the dosage and dosage forms, and the marketing approval dates. After the corresponding brand-name drugs are determined, I used the Authorized Generics List ${ }^{7}$ to find out if these brand-name drug companies had ever launched authorized generics.

\footnotetext{
http://www.fda.gov/Drugs/DevelopmentApprovalProcess/ HowDrugsareDevelopedandApproved/DrugandBiologicApprovalReports/ ANDAGenericDrugApprovals/ucm050527.htm.

${ }^{6}$ http://www.accessdata.fda.gov/scripts/cder/ob/eclink.cfm. 7 http://www.fda.gov/Drugs/DevelopmentApprovalProcess/ HowDrugsareDevelopedandApproved/ApprovalApplications/ AbbreviatedNewDrugApplicationANDAGenerics/ucm126389.htm.
} 
I conjecture that the switching cost from the brand-name drugs to the generics mainly comes from two factors, "unwilling to switch" and "unable to switch". "Unwillingness to switch" to a generic means that a consumer feels a mental and psychological attachment to the brand-name drug. I measure the degrees of consumer attachment by the times during which there were no other drugs than the brand-name drugs on the markets, that is, the length of time between the date a brand-name drug was approved and the date its first generic was approved. As is mentioned in the introduction, drugs are credence goods. It takes time for consumers to develop affinities to drugs. Drugs for acute conditions may have immediate curing effects. However, the same conditions often recur over time, requiring the consumer to take the same drug (since the brand-name drug is the only drug available of its kind before the generic entry) repeatedly. Each time of use can make the consumer feel more confident about the drug's efficacy. Similarly, for chronic illnesses, a longer-term continual use of a brand-name drug may give a consumer a better understanding of its effects on her health. As these cases imply, the longer the brand-name drugs have been marketed, the greater the degree of confidence a consumer has in their efficacy. Hence the length of time the brand-name drug has been marketed can serve as a proxy for the consumer switching costs.

However, the brand-name marketing time before generic entry cannot be used to measure the "mental and psychological attachment" to OTC drugs. OTC drugs are previous prescription drugs that have been made available over the counter after long marketing periods with established safety records. From the pre-generic marketing time, we only know how long the OTC version had been on the market before the first generic OTC enters., We do not know, however, how long the prescription version had existed on the market, at home or abroad, before the OTC version first 
appeared. For this reason, my data set comprises only the data for prescription drugs.

The other factor defining a consumer switching cost is the consumer's inability to switch. Inability to switch means that a consumer has limited freedom to choose among different versions (the brand-name version or the generic substitutes) of the drug. I consider that all the drugs fall into two categories: hospital use and home use. Hospital use drugs are used administered in hospitals, mainly provided by caregivers, during surgery or medical tests. On the other hand, home use drugs are those patients administer themselves at home, like taking tablets orally, applying cream on the skin. Usually patients who take hospital use drugs are more constrained in their choices. First, those who receive hospital treatments are more likely to be in emergency, and therefore take whatever drugs they are given. Second, their choices are limited by the hospital's pharmacy: it is possible that the hospital does not carry the drugs they want to switch to. Third, treatments provided by a caregiver usually involve more complex procedures. Given their limited knowledge, patients are more likely to leave the choice of drugs to the doctors. In contrast, patients who take home use drugs have more freedom to choose. With prescriptions, they can go to a pharmacy they like best or even an online pharmacy, and choose to get a brand-name drug or a generic substitute. Therefore, home use drugs should have lower switching costs relative to hospital use drugs.

To decide which drugs are for Hospital Use and which are for Home Use is not an easy task, however. To do that, I looked up each drug online to determine its uses, and I then used the following criteria for classifications. Drugs used in surgery, or other treatments mainly practiced by caregivers, injection, for example, are considered Hospital Use drugs; otherwise they are considered for "Home Use". For example, Ultane (inhalation liquid) is an anesthesia used before surgery. Therefore 
it is classified as a "Hospital Use" drug. Similarly, Rimso-50 (intraversical solution) is used for bladder instillation, which I classify as a "Hospital Use" drug, though some patients might practice bladder instillation at home. Sometimes, the "dosage forms" can be useful to determine drugs' uses. For example, Amicar is used to control bleeding during or after a surgery. While Amicar Injection is grouped as "Hospital Use", Amicar Tablet is grouped as "Home Use". Compared to injections, tablets are taken orally and require a longer time before taking effect, so they should not be used to treat serious bleeding problems, or used in emergencies, like during a surgery. Also the instruction further implies that Amicar Tablets should only be used to treat mild bleeding problems after a small surgery, like dental surgeries, which can be practiced by patients on their own in a less urgent situation.

Table 1 below summaries the characteristics of the three variables in my dataset.

\begin{tabular}{|c|c|c|c|c|c|}
\hline & Count & Mean & s.d. & Min & Max \\
\hline ag & 202 & .282 & .451 & 0 & 1 \\
inp & 202 & .198 & .399 & 0 & 1 \\
mono_month & 202 & 141.018 & 70.564 & 21.767 & 256.433 \\
\hline
\end{tabular}

Table 2.1: Summary results

The dataset has 202 observations. ag, a dummy variable, denotes brand-name firm's decision on launching AG, 1 for "launch", 0 for "not launch". The mean of ag is 0.282 , showing that out of the 202 brand-name drugs about $28.2 \%$ has launched AG. "inp", another dummy variable, 1 for "Hospital Use", 0 for "Home Use", denotes whether a drug is taken in treatments mainly practiced at hospital. This variable is intended to represent consumers' "easiness to switch". The mean of "inp" shows that, out of the 202 drugs, 19.8\% are made mainly for "Hospital Use". "mono_month", measured in months, denotes the length of brand-name drug marketing periods before generic entry. This variable captures consumers' unwill- 
ingness to switch (brand loyalty). The mean of mono_month is about 12 years (141 months), which is consistent with the fact that the average brand-name marketing time before generic entry is 13 years. The row of mono_month suggests substantial variations in the length of pre-generic marketing time across different brand-name drugs.

\subsubsection{Methodology}

I assume whether or not a brand-name company launches authorized generics is related to the switching cost its consumers has to pay to switch to a new drug. I treat the decision to launch authorized generics as a binary variable, $Y_{i}$, which equals 1 if brand-name drug i launches authorized generics, 0 if not. A probit model is built to analyze the determinants of such a decision. The probability of launching an authorized generic is defined as:

$$
P\left(Y_{i}=1 \mid X_{i}, \epsilon_{i}\right)=\Phi\left(X_{i} \beta+\epsilon_{i}\right)
$$

where $X_{i}$, a vector of regressors, contains observed factors that explain the decision of launching authorized generics, while $\epsilon_{i}$, with $\epsilon \sim N(0,1)$, an error term, captures the effect of unobserved factors on such decisions. $\beta$ is a vector of coefficients to be estimated. $\Phi$ is the CDF of the standard normal distribution.

\subsubsection{Results}

In my probit regressions, the dependent variable, ag, is 1 whenever an authorized generic is launched for brand-name drug i. The independent variables are lnmono_month (log-linearized mono_month) and inp. As I have mentioned in section 5.1, mono_month, denoting the length of pre-generic marketing period of brandname drug i, is a continuous variable, so is its log-linearized version lnmono_month. 
inp is a dummy variable, which equals 1 when drug $\mathrm{i}$ is made mainly for Hospital Use, 0 otherwise. Table 2 below shows the results:

\begin{tabular}{|c|c|c|c|}
\hline ag & Coefficient & Std. Err. & $P>z$ \\
\hline inp & -.769 & .293 & .007 \\
lnmono_month & -.341 & .139 & .015 \\
\hline
\end{tabular}

Table 2.2: Estimation results : regress

The coefficient of the variable inp is negative, which means if a drug is made mainly for Hospital Use, the brand-name company would be less likely to launch an authorized generic. The coefficient of the variable lnmono_month is negative, which means that, if a brand-name drug has a longer pre-generic marketing period, the brand-name company would be less likely to launch an authorized generic. The results are significant as the p-values are less than the cutting value 0.05 .

Brand-name firms' strategy of launching an AG is to use lower price to attract consumers who would not buy brand-name drugs. For Hospital Use drugs, consumers do not have much freedom to choose. Instead, it is usually the doctors who make choices. Doctors are relatively less sensitive to price changes than patients. Therefore for hospital-use drugs, brand-name firms are more likely to influence the doctors to stay with their brand-name drugs instead of lowering prices to compete with generics.

When it comes to Home Use drugs, consumers have more freedom to choose, and therefore the strategy to launch an AG is more important in competition with generics. However, launching an AG leads to lower prices and erodes the brandname drug's customer base, as some customers in the base are tempted to switch to low-priced generics. This dilemma can be resolved if the brand-name companies can figure out how much more the higher-end customers would like to pay for the brand-name drugs. The results of my test show that the length of the pre-generic 
marketing periods of the brand-name drugs may serve as a good proxy for the how much more. If consumers have had longer experiences of the brand-name drugs, they would value them considerably more (than generic substitutes). In this situation, brand-name firms might find it more profitable to exploit the higher end alone, which renders the launch of AG less likely. On the other hand, if consumers have had relatively short experience of the brand name drugs, they would value the brand-name drugs not much more (than the generic substitutes). In this situation, brand-name firms might find it more profitable to expand their business to the lower end market with the launch of AG.

\subsection{Conclusions}

When there is generic competition the brand-name companies sometimes (but not always) launch generic versions themselves possibly through a third party. Such generics are called authorized generics to be distinguished from general (unauthorized) generics. In this paper I investigate the rationale for such a strategy. To account for the two puzzles noted in the introduction, I focus on the role of the customer bases the brand-name companies develop prior to generic entry. I present a two-period model in which the incumbent develops a customer base as a monopoly in the first period and readies itself for generic competition in the second period.

I find that, when the switching cost is high, the incumbent creates a larger customer base by producing output beyond the short-run optimum. The sub-optimal profit in the first period is more than offset as it allows the brand-name company to retain a large number of loyal customers willing to pay higher prices for the brandname drugs than switching to the generics. Comparatively, when the switching cost is low, the incumbent does not make such a short-run sacrifice, as it is more 
difficult to keep the customer base intact upon generic entry. Authorized generics provide the incumbent with a means to compete with the generic entrant for the low-end consumers, who would not pay for the high- priced brand-name drug. However, authorized generics will reduce the profit of the brand-name drugs on the high-end consumers, because the additional competition due to the launching of the authorized generic brings down the price of the generics further. Thus, when the switching cost is low enough that a reduction in the profit of the brand-name drug is exceeded by the profit of the authorized generic, the incumbent launches the AG for the higher combined profit.

From the results above, I conclude that the brand-name company launches the authorized generics only when the switching cost is small enough. When the switching cost is high, the incumbent sells more than the short-run profit-maximizing quantity in the first period to develop a larger customer base it can capitalize on in the second period. This strategy does not work however if the switching cost is low, however, the customer bases is more vulnerable to price competition, Therefore it makes more sense for the brand-name company to compete with the generic entrant in the lower end market with the authorized generic. The probit regression analysis gives empirical results largely consistent with the results from the theoretical analysis. 


\section{CHAPTER 3}

\section{THE MERGER PARADOX AND R\&D}

\subsection{Introduction}

Merger is one of the most salient features of the pharmaceutical industry during the last quarter-century. Grabowski and Kyle (2008), for example, that global share of the top ten pharmaceutical firms increased from 28.3 percent in 1989 to 48.3 percent in 2004. What has caused this trend is still debated. One hypothesis is that it is due to rising $\mathrm{R} \& \mathrm{D}$ costs. Another points to increased competition from generics possibly intensified by the Hatch-Waxman Act. In this chapter I examine if these casual explanations make sense in light of the existing theory of merger.

Unfortunately, however, there is no unique theory that explains merger cases satisfactorily. In fact, modern theory of merger is a poor tool for understanding real-world merger cases mainly because it is not easy to explain why merger is profitable within the framework of simple models of oligopoly. This so-called "merger paradox" originates from the work of Salant et al. (1983), who discovered that a profitable merger in symmetric Cournot oligopoly requires the participation of more than 80 percent of firms in industry. According to this "80 percent rule", most mergers we observe in the real world - mergers between two or three firms - are unprofitable, thereby leading to the paradox. Since the SSR study, a number of ways out of the merger paradox have been proposed. For example, Daughety (1990) has shown that merger among symmetric Cournot firms could be profitable if the merged firm assumes the role of the Stackelberg leader while all others act as followers in the post-merger industry. Perry and Porter (1985) have considered the model where firms are endowed with asymmetric amounts of capital, and found that the merger among small firms can be profitable if the pooling of their capital assets leads 
to a sufficient cost reduction for a new firm. ${ }^{1}$ Similarly, Compte et al. (2002) have demonstrated the profitability of merger among asymmetric Bertrand firms. Davidson and Deneckere (1986) have shown that the merger among symmetric firms in a Salop-type spatial model of price competition can be profitable. More recent work has considered increasingly complicated merger settings: merger under the threat of entry (Pesendorfer, 2005) and successive mergers (Nocke and Whiston, 2013), for example.

The objective of the present chapter is to reconsider the profitability of horizontal merger under symmetric Cournot oligopoly with a new twist: R\&D opportunities. The basic model has two stages; firms first invest in cost-reducing R\&D and then compete in quantities in the homogeneous product market. We then allow an arbitrary number of firms to merge before, or in anticipation of, the arrival of $R \& D$ opportunities. Our first result is that if all R\&D firms merge into a single firm in the presence of non-R\&D firms, then such merger is profitable, regardless of the number of firms in the industry. We can interpret this result loosely in a context where new ideas for inventing a new drug arrive to a few firms in the industry in a Poisson process over time. Then these firms receiving news prefer to merge before investing in R\&D. At some future date, another idea is received by a group of firms, which go on to merge before undertaking investment in R\&D. Interpreted this way, our theory is consistent with the current trend for merger not only in the pharmaceutical industry but in many other R\&D intensive industry.

We then turn out attention to the possibility of profitable merge among a subset of R\&D firms, and find that in this case there re-emerges something similar to the

\footnotetext{
${ }^{1}$ They also considered mergers among firms that constituted the competitive fringe in the dominant-firm setting.
} 
notorious SSR rule, although the threshold is lower than $80 \%$. If the number of merging firms surpasses this new threshold, merger is unprofitable.

\subsection{A single R\&D firm and merger}

Consider an n-firm industry $(n \geq 3)$. All firms face identical marginal cost fixed at $c>0$. We then suppose that one firm, say, firm 1, finds the opportunity to invest in cost-reducing R\&D. The R\&D technology is familiar (e.g., d'Aspremont and Jacquemin 1988); that is, investing quantity $x_{1}$ in R\&D reduce firm 1 's marginal cost to $c-x_{1} \equiv c_{1}$ at the quadratic R\&D cost $g x_{1}{ }^{2}$, where $g$ is a positive constant and captures the efficiency of R\&D technology. Without merger, the game develops as follows. In stage one firm 1 first makes R\&D investment, and all other firms observe the new cost $c_{1}$ In stage two, all firms play a simultaneous quantity-setting (Cournot) game in the product market. Consumers regard all the goods as homogeneous. Demand is assumed linear and is given by $p=a-Q$, where $a>c$ and $Q$ is industry output. In this setting we consider the incentives for firm 1 to merge with $\mathrm{m}$ firms, where $1 \leq m \leq n-1$. The game sequence with merge is as follows. In the first stage, firm 1 and $\mathrm{m}$ non-R\&D firms merge into a new firm, and then the new firm makes an $R \& D$ decision. In the second stage, the new firm and all the other $n-m$ firms play a Cournot game. The merger paradox says that unless a proposal of merger involves more than $80 \%$ of $n$ firms there is no incentive to merge. We examine how this so-called $80 \%$ rule is affected by $\mathrm{R} \& \mathrm{D}$ opportunities.

As a benchmark, consider the case without merger. It is a routine exercise to show that in stage two firm 1 receives the net profit

$$
\begin{aligned}
\pi_{1} & =\left[\left(a-n\left(c-x_{1}\right)+(n-1) c\right]^{2} /(n+1)^{2}-g x_{1}{ }^{2}\right. \\
& =\left(a-c+n x_{1}\right)^{2} /(n+1)^{2}-g x_{1}{ }^{2}
\end{aligned}
$$


where $x_{1}$ is taken as given. All other firms $j \neq 1$ make the symmetric profit

$$
\pi_{j}=\left(a-c-x_{1}\right)^{2} /(n+1)^{2} .
$$

In stage one firm 1 choose $x_{1}$ to maximize (3.2), yielding the first-order condition

$$
n\left(a-c+n x_{1}\right) /(n+1)^{2}-g x_{1}=0 .
$$

The second-order is satisfied if

$$
g>n^{2} /(n+1)^{2}
$$

Eq (3.4) yields the optimal investment level for firm 1:

$$
x_{1}^{*}=n(a-c) /\left[g(n+1)^{2}-n^{2}\right] .
$$

We want to make sure that new marginal cost $c_{1}=c-x_{1}$ is non-negative. Substitution from (3.6), we write this non-negativity condition as:

$$
g \geq n(n-1+a / c) /(n+1)^{2} .
$$

Given $a>c$, condition (3.7) implies condition (3.5). Thus, below we assume that $g$ satisfies condition (3.7). Substituting from (3.6) into (3.2) yields the maximized profit for firm 1:

$$
\begin{aligned}
\pi_{1}^{*} & =(a-c)^{2}\left[g^{2}(n+1)^{2}-g n^{2}\right] /\left[g(n+1)^{2}-n^{2}\right]^{2} \\
& =(a-c)^{2} g /\left[g(n+1)^{2}-n^{2}\right] .
\end{aligned}
$$

The equilibrium profit to a non-R\&D firm obtains from substituting from (3.6) into $(3.3)$ :

$$
\pi_{j}^{*}=(a-c)^{2}[g(n+1)-n]^{2} /\left[g(n+1)^{2}-n^{2}\right]^{2} .
$$

A non-R\&D firm makes a positive profit if and only if $g(n+1)>n$, or

$$
g>n /(n+1)
$$


Calculations show that condition (3.11) is more restrictive than condition (3.7) if and only if $2 c>a$; i.e., if the initial cost is relatively high, condition (3.11) gives the lower bound on $g$; otherwise, the lower bound is given by (3.7).

We now examine the profitability of merger between firm 1 and $m$ non-R\&D firms prior to the R\&D stage. The merger reduces the total number of firms in the industry to $n-m$, including the new firm. After merger, the new firm makes investment in R\&D using the inherited R\&D technology. Then all firms engage in Cournot competition.

The equilibrium with merger is identical to the one without merger obtained above, except that the number of firms shrinks to $n-m$ firms in the industry. Thus, by (3.9) the new firm has the profit

$$
\pi^{*}(m)=(a-c)^{2} g /\left[g(n-m+1)^{2}-(n-m)^{2}\right]
$$

Further, the right-hand side of (3.7) is increasing in $n$, and so condition (3.7) implies that the new firm faces a positive marginal cost.

If there is no merger, firm 1 and $m$ firms would have the combined profit $\pi_{1}{ }^{*}+$ $m \pi_{j}^{*}$. Substituting from (3.9) and (3.10), we can write this sum as

$$
\pi_{1}{ }^{*}+m \pi_{j}{ }^{*}=(a-c)^{2}\left\{\left[g^{2}(n+1)^{2}-g n^{2}\right]+m[g(n+1)-n]^{2}\right\} /\left[g(n+1)^{2}-n^{2}\right]^{2} .
$$

If $\pi^{*}(m)>\pi_{1}^{*}+m \pi_{j}^{*}$, we say that the merger is profitable.

The profit difference $\pi^{*}(m)-\left[\pi_{1}{ }^{*}+m \pi_{j}{ }^{*}\right]$ generally depends not only on $m$, the number of participating firms in the merger but also on $n$, the total number of firms in the industry, as well as on $g$, the R\&D technology. With the result depending on so many parameter values, the general conclusion is difficult to find. However, we find a very strong result that demonstrates that merger is profitable for any $m$ and any $n$. 
Proposition 3.1 Atg=1 a merger between the (unique) RESD firm and any number $m$ of non-RछD firms is profitable.

Proof. First, $g=1$ satisfies condition (3.7). Substitution yields

$$
\begin{aligned}
& \pi^{*}(m)=(a-c)^{2} /(2 n-2 m+1) \\
& \pi_{1}{ }^{*}+m \pi_{j}^{*}=(a-c)^{2}(2 n+1+m) /(2 n+1)^{2} .
\end{aligned}
$$

Hence, since $n>m$,

$$
\pi_{1}{ }^{*}(m)-\left(\pi_{1}{ }^{*}+m \pi_{j}{ }^{*}\right)=(a-c)^{2} m(2 n-2 m+1) /\left[(2 n-2 m+1)(2 n+1)^{2}\right]>0 .
$$

In general, $\mathrm{g}$ has the lower bound reflecting the requirement that $\mathrm{g}$ has to be high enough to keep the post-R\&D cost non-negative as in condition (9). $\mathrm{g}$ is also bounded from the above because higher g makes R\&D less profitable so that the effect of R\&D is swamped by the $80 \%$ rule. However, we prove the following general result (see Appendix for the proof).

Proposition 3.2 For any number of firms in the industry, there is always a profitable merger between the RED firm and any number of non-RED firms.

For $g \neq 1$ our model also exhibits the feature that is akin to of the merger paradox. Although we can always find a profitable merger with any number of partners regardless of the total number of firms in the industry, if we hold $n$ fixed, merger is less likely to be profitable, the smaller the number of participating nonR\&D firms. More specifically, we show in the appendix that as $n$ increases, the range of $g$ in which two-firm merger is profitable shrinks and converges to one as $n$ goes to infinity. 
To better understand the role of $R \& D$ in the merger paradox, we next compare our results with those obtainable from the case in which cost asymmetry is exogenous. Suppose thus that firm 1 has exogenously low cost $\left(c_{1}\right)$ relative to other firms, all of which have cost $c>c_{1}$. Then, merger between firm 1 and one high-cost firms is not always profitable. We show it in the environment most favorable to merger; $n=3$. Without merger firm 1 earns the profit

$$
\pi_{1}=\left(a-3 c_{1}+2 c\right)^{2} / 16
$$

while a high-cost firm receives the profit

$$
\pi_{j}=\left(a-2 c+c_{1}\right)^{2} / 16 .
$$

When firm 1 merges with one high-cost firms, the new firm uses firm 1's low-cost technology, Hence, the new firm's profit is

Then, as $c_{1} \rightarrow c, \bar{\pi}_{1}-\left(\pi_{1}+\pi_{j}\right) \rightarrow(a-c)^{2} / 9-(a-c)^{2} / 8<0$. Thus, two-firm merger can be unprofitable under exogenous cost asymmetry whereas for $g=1$ merger between two firms is always profitable for any $n$.

\subsection{Multiple R\&D firms and merger}

We now consider the industry with $k \mathrm{R} \& \mathrm{D}$ firms, where $2 \leq k<n$. As before, we begin with the case without merger. The game is familiar. In stage one $k(<$ $n-1$ ) firms simultaneously choose levels of investment $x_{i}$ in $\mathrm{R} \& \mathrm{D}$, which reduces the marginal cost from $\mathrm{c}$ to $c_{i}=c-x_{i}$ for firm i. The other $(n-k)$ firms do not engage in $\mathrm{R} \& \mathrm{D}$ and hence have the null action set in the first stage. In stage two,

all $n$ firms obvers all costs and play a quantity-setting (Cournot) game, given the marginal costs $c_{i}$ for $\mathrm{R} \& \mathrm{D}$ firms $\mathrm{i}$ and $c$ for non-R\&D firms. In the second-stage 
game, firm j has the profit

$$
\pi_{j}=\left[a-(k+1) c+\sum_{i \in K} c_{i}\right]^{2} /(n+1)^{2}
$$

if it is a non-R\&D firm and

$$
\pi_{j}=\left[a-n c_{j}+(n-k) c+\sum_{i \in K} c_{i}\right]^{2} /(n+1)^{2}-g x_{j}^{2}
$$

if it is an R\&D firm, where $K$ denotes the set of R\&D firms and $K_{-j}$ is the set obtained by deleting R\&D firm $\mathrm{j}$ from the set $K$. In the first-stage, all firms $j \in K$ simultaneously choose their investment levels $x_{j}$ in R\&D to maximize the net profit

$$
\pi_{j}=\left[a-n\left(c-x_{j}\right)+(n-k) c+\sum_{i \in K_{-j}} c_{i}\right]^{2} /(n+1)^{2}-g x_{j}^{2}
$$

where $g x_{j}^{2}$ is the quadratic R\&D cost. The first-order condition is

$$
n\left[a-n\left(c-x_{j}\right)+(n-k) c+\sum_{i \in K_{-j}} c_{i}\right] /(n+1)^{2}-g x_{j}=0
$$

Focusing on the symmetric equilibrium, we can solve for the equilibrium symmetric R\&D level, $x^{*}$.

$$
x^{*}=n(a-c) /\left[g(n+1)^{2}-n(n-k+1)\right]
$$

Substituting $x^{*}$ into (??) and rearranging, we can write the representative $R \& D$ firm's symmetric equilibrium profit as

$$
\pi^{*}(k)=g(a-c)^{2}\left(g(n+1)^{2}-n^{2}\right) /\left[g(n+1)^{2}-n(n-k+1)\right]^{2}
$$

where the firm subscript $j \in K$ is suppressed under symmetry.

Suppose next that all the R\&D firms in the set $K$ merge to form a new firm before the R\&D stage. Merger reduces the total number of firms to $n-k+1$. In the first stage the new firm, which we call firm 1 , chooses the quantity $x_{1}$ to invest 
in R\&D. In the second stage all firms play a Cournot game. We can express the new firm's first-period profit as

$$
\pi_{1}(k)=\left[a-c+(n-k+1) x_{1}\right]^{2} /(n-k+2)^{2}-g x_{1}^{2},
$$

In the first stage the new firm chooses $x_{1}$ to maximize (10). The first-order condition is

$$
(n-k+1)\left[a-c+(n-k+1) x_{1}\right] /(n-k+2)^{2}-g x_{1}=0 .
$$

The (symmetric) equilibrium R\&D level is expressed as

$$
\hat{x}(k)=(n-k+1)(a-c) /\left[g(n-k+2)^{2}-(n-k+1)^{2}\right] .
$$

Substituting $\hat{x}(k)$ into (3.16) yields, after rearranging, the following symmetric equilibrium profit:

$$
\hat{\pi}(k)=g(a-c)^{2} /\left[g(n-k+2)^{2}-(n-k+1)^{2}\right] .
$$

The above analysis makes sense if $\hat{x}(k)$ and $\hat{\pi}_{1}(k)$ are positive. Thus we assume

$$
g>(n-k+1)^{2} /(n-k+2)^{2} .
$$

. The right-hand side increases in $n$, approaching the limit of 1 .

We now compare the profits $\hat{\pi}(k)$ and $k \pi^{*}(k)$ for the possibility of profitable merger among R\&D firms. As discussed in the preceding section, the profit difference in general depends on the value of $k, n$ and $g$. The sharpest result again obtains at $g=1$, which is necessary for $g$ to satisfy the lower bound for all $n$.

Proposition 3.3 At $g=1$ merger of all RED firms is profitable, regardless of the $k / n$ ratio.

Proof. $\hat{\pi}(k)-k \pi^{*}(k)>0$ if and only if

$$
\left[(n+1)^{2}-n(n-k+1)\right]^{2}>k\left[(n-k+2)^{2}-(n-k+1)^{2}\right]\left[(n+1)^{2}-n^{2}\right] .
$$


Writing $n+1=q$, this condition is equivalent to

$$
\begin{aligned}
& {\left[\left(q^{2}-(q-1)(q-k)\right]^{2}-k\left[(q-k+1)^{2}-(q-k)^{2}\right]\left[q^{2}-(q-1)^{2}\right]\right.} \\
= & {\left[\left(q^{2}-(q-1)(q-k)\right]^{2}-k(2 q-2 k+1)(2 q-1)\right.} \\
= & (k-1)\left[\left(q^{2}(k-1)+k(2 q-1)\right]>0 .\right.
\end{aligned}
$$

Proposition 3.4 has the following explanation. Without R\&D a k-firm merger decreases the combined profit and hence is unprofitable, if the ratio $\mathrm{k} / \mathrm{n}$ falls below the Salant-Switzer-Reynolds (SSR) 80-percent threshold. However, with R\&D opportunities, merger generates three additional effects in favor of merger. First, it allows firms to economize on the R\&D cost ( $R \& D$ cost-saving effect). Second, since merger decreases the number of firms, each firm earns a greater gross profit, given marginal cost, which makes investment in R\&D more profitable (profit expansion effect). Third, a cost reduction leads to an output expansion, causing non-R\&D firms to contract their output (market-share-expansion effect). If all R\&D firms merge, Proposition 1 says that the sum of these effects more than offset the SSR effect, even though the $k / n$ ratio falls short of the SSR threshold, making the post-merger profit greater than the sum of the pre-merger profits.

To understand the implications R\&D has on the success of merger, we demonstrate that if cost asymmetry merger is exogenous, merger need not be profitable. Again we consider the case most in favor of merger most; let $n=3$ and $k=2$ firms have low cost $c_{L}$ while the other firm has high cost $c>c_{L}$. Without merger each of the two low cost firms earns the profit $\pi_{L}=\left(a-2 c_{L}+c\right)^{2} / 16$ while after merging the new firm earns the profit $\pi_{N}=\left(a-2 c_{L}+c\right)^{2} / 9$. Thus, as $c_{L} \rightarrow c$, $\pi_{N}-2 \pi_{L} \rightarrow(2-c)^{2} / 9-(2-c)^{2} / 8<0$. Thus, merger of two exogenously low cost 
firms need not be profitable, whereas if cost asymmetry is a consequence of R\&D, merger is profitable.

The analysis in the preceding section implies that $g$ also has upper bounds that depend on the size of $n$ (and her on the size of $k$ ). As shown there, for given $k$, the range of $g$ that makes merger profitable shrinks as $n$ is increased and converges to one as $n$ approaches infinity. Thus, we still have the general observation that with the total number of firms in the industry fixed at $n$, a two-firm merger is the most difficult to make profitable. In the next section, therefore, we focus on merger involving two R\&D firms but ask the question concerning partner selection.

\subsection{Two R\&D firms}

In this subsection we assume that there are two R\&D firms and $n-2$ non- $\mathrm{R} \& \mathrm{D}$ firms in industry. Our focus is whether these two firms find it more attractive to merge with each other or whether each of them prefers to merge with a non-R\&D firm. To keep things simple, we set $g=1$. The two R\&D firms, i and $\mathrm{j}$, choose investments in R\&D to maximize the profits

$$
\begin{aligned}
& \pi_{i}=\left(a+n x_{i}-c-x_{j}\right)^{2} /(n+1)^{2}-x_{i}^{2}, \\
& \pi_{j}=\left(a+n x_{j}-c-x_{i}\right)^{2} /(n+1)^{2}-x_{j}^{2} .
\end{aligned}
$$

The first order conditions are

$$
2\left(a-c+n x_{i}-x_{j}\right) /(n+1)^{2}-2 x_{i}=0,2\left(a-c+n x_{j}-x_{i}\right) /(n+1)^{2}-2 x_{j}=0 .
$$

Solving for $x_{i}$ and $x_{j}$, we have

$$
x^{*}=x_{i}=x_{j}=n(a-c) /(3 n+1) .
$$

Therefore, replacing $x_{i}$ and $x_{j}$ in the profit function for $\mathrm{i}$ and $\mathrm{j}$, we have

$$
\pi_{i}=\pi_{j}=(2 n+1)(a-c)^{2} /(3 n+1)^{2} .
$$


For a non-R\&D firm, the profit function is

$$
\pi_{n}=\left(a-c-x_{i}-x_{j}\right)^{2} /(n+1)^{2}
$$

Plugging $x^{*}$ into the function, we calculate the profit for a non-R\&D firm

$$
\pi_{n}=(a-c)^{2} /(3 n+1)^{2}
$$

If two R\&D firms merge, the post-merger profit for the merged firm is

$$
\pi_{M}=(a-c)^{2} /[2(n-1)+1]=(a-c)^{2} /(2 n-1),
$$

which means that each makes

$$
\pi_{M} / 2=(a-c)^{2} /(4 n-2)
$$

If each R\&D firm merges with a non-R\&D firm, there are two merged firms, each of which makes

$$
\pi_{N M}=(2 n-3)(a-c)^{2} /(3 n-5)^{2}
$$

When an R\&D firm and a non-R\&D firm merge, we need to assign the benefits of the merger to each firm in order to determine whether the merger is profitable or not. Since this involves asymmetric firms we assume that the benefits of the merger is negotiated under the Nash bargaining rule with equal weights. Thus, let $B_{R}$ denote the benefit to the R\&D firm and $B_{N}$ be that of the non-R\&D firm. Then,

$$
B_{R}+B_{N}=\pi_{N M}
$$

Nash bargaining results in equalization between the firms of the differences between the benefit of successful bargaining and the profit each receives when bargaining fails. That is, $B_{R}$ and $B_{N}$ satisfy the following equation

$$
B_{R}-(2 n+1)(a-c)^{2} /\left[2(3 n+1)^{2}\right]=B_{N}-(a-c)^{2} /\left[2(3 n+1)^{2}\right]
$$


Collecting terms, we find the value of the merger to an R\&D firm

$$
B_{R}=(a-c)^{2}\left[(2 n-3) /(3 n-5)^{2}+(2 n+1) /(3 n+1)^{2}-1 /(3 n+1)^{2}\right] / 2 .
$$

Similarly, the value of the merger to a non-R\&D firm

$$
B_{N}=(a-c)^{2}\left[(2 n-3) /(3 n-5)^{2}-(2 n+1) /(3 n+1)^{2}+1 /(3 n+1)^{2}\right] / 2 .
$$

We next compare $B_{R}$ with $\pi_{M} / 2$, the profit per R\&D firm if the two R\&D firms merge with each other. If (and only if) $B_{R}>\pi_{M} / 2$, then, we conclude that each R\&D firm prefers to merge with a non-R\&D firm rather than to merge with each other.

Proposition 3.4 (A) When $n=4$, it is more profitable for the RED firm to merge with the non-RED firm; (B) When $n \geq 5$, it is more profitable for the RED firms to merge with each other.

Proof.

$$
\begin{aligned}
& B_{R}-\pi_{M} / 2 \\
= & (a-c)^{2}\left[(2 n-3) /(3 n-5)^{2}+(2 n+1) /(3 n+1)^{2}-1 /(3 n+1)^{2}-1 /(2 n-1)\right] / 2 \\
= & (a-c)^{2}\left\{\left(-9 n^{4}+30 x^{3}+89 n^{2}-160 x-22\right) /\left[(3 n-5)^{2}(3 n+1)^{2}(2 n-1)\right]\right\} / 2 .
\end{aligned}
$$

Let $F(n)$ denote the numerator of the fraction in brackets. By Descartes' rule of signs, this function has 2 sign changes in the sequence of coefficients. $-F(n)$ also has two sign changes. Thus, $F(n)$ has two positive roots and two negative roots. The two positive roots are $n \approx 1.53$ and $n \approx 4$.62. Calculations show that $F(4)>0>F(5)$. 


\subsection{Conclusions}

Motivated by the long-run trend to merge in the pharmaceutical industry, we reconsider the merger paradox, which states that, unless a majority of firms in industry merges into one firm, mergers are not profitable. While a number of authors took up the challenge of resolving the merger paradox, no one has explored the relationship between $R \& D$ and merger. In this chapter we show that when there is one firm that does $R \& D$ then that firm has an incentive to merge with any number of non-R\&D firms. In light of the paradox then, two firms (one R\&D and one non-R\&D) have the incentive to merge, regardless of the total number of firms in industry. Our second result is that if there are multiple $R \& D$ firms and multiple non-R\&D firms in industry, all R\&D firms have the incentive to merge even though their number does not reach the $80 \%$ threshold. Finally, we consider the choice of partners for two R\&D firms when there are 2 or more non-R\&D firms. We find that when there are only two non-R\&D firms in industry, each R\&D firms prefer to merge with a non-R\&D firm. However, if there are 3 or more than non-R\&D firms, then they prefer to merge with each other than with a non-R\&D firm.

This research can be extended in a number of directions. First, we can explore the more general case in which there are $\mathrm{k} R \& \mathrm{D}$ firms and $n-k$ non-R\&D firms and consider the merger incentives of a subset $m(<k)$ of $\mathrm{R} \& \mathrm{D}$ firms. While there may be any clear-cut answers to this question due to the number of free parameters, numerical analysis may be applied to find some general results. Secondly, the simple structure of the present analysis allows one to add more structures. One possible extension in this direction is the effect of $R \& D$ spillovers in the sense of d'Aspremont and Jacquemin (1988); the main query is whether the existence of spillovers is a friend or a foe for successful merger. 


\section{BIBLIOGRAPHY}

Appelt, S. (2010). Authorized generic entry prior to patent expiry: Reassessing incentives for independent generic entry. SFB/TR 15 Discussion Paper $35 \%$.

Baye, M. R., Crocker, K., and Ju, J. (1996). Divisonalization, franchising, and divestiture incentives in oligopoly. American Economic Review, 86:223- 236.

Berndt, E. R., Mortimer, R., and Parece, A. (2007). Do authorized generic drugs deter paragraph iv certification? recent evidence. Working Paper.

Chen, T. (2007). Authorized generics: A prescription for hatch- waxman reform. Virginia Law Review, 93:459-513.

Choi, J. P. (1998). Patent litigation as an information-transmission mechanism. American Economic Review, 88:1249-1263.

Compte, O., Jenny, F., and Rey, P. (2002). Capacity constraints, mergers, and collusion. European Economic Review, 46:1-29.

d'Aspremont, D. and Jacquemin, A. (1988). Cooperative and non-cooperative R\&D in duopoly with spillovers. American Economic Review, 78:1133-1137.

Daughety, A. F. (1990). Beneficial concentration. American Economic Review, $80: 1234-1237$.

Davidson, C. and Deneckere, R. (1986). Long-run competition in capacity, short-run competition in price, and the cournot model. The RAND Journal of Economics, 17(3):404-415.

Grabowski, H. and Kyle, M. (2008). Mergers and alliances in pharmaceuticals: effects on innovation and r\&d productivity. The Economics of Corporate Governance and Mergers, 262.

Iizuka, T. (2008). Generic entry in a regulated pharmaceutical market. Japanese Economic Review, 60:63-81.

Iizuka, T. (2012). Physician agency and adoption of generic pharmaceuticals. American Economic Review, 102:2826-2853.

Klemperer, P. (1987). Markets with consumer switching costs. The Quar-terly Journal of Economics, 102(2):375-394.

Lemely, M. A. and Shapiro, C. (2005). Probabilistic patents. The Journal of Economic Perspectives, 19:75-98.

Mossinghoff, G. J. (1999). Overview of the hatch-waxman act and its impact on drug development process. Food Drug Law Journal, 54:187-194. 
Nocke, V. and Whiston, M. (2013). Merger policy with merger choice. American Economic Review, 103:1006-1033.

Perry, M. K. and Porter, R. H. (1985). Oligopoly and the incentive for horizontal merger. American Economic Review, 75:219-227.

Pesendorfer, M. (2005). Merger under entry. Rand Journal of Economics, 36:661679.

Reiffen, D. and Ward, M. R. (2005). "branded generics" as a strategy to limit cannibanization of pharmacetical markets. Managerial and Decision Economics, 28(4-5):251-265.

Salant, S., Switzer, S., and Reynolds, R. (1983). Losses from horizontal merger: the effects of an exogenous changes in industry structure on cournot-nash equilibrium. Quarterly Journal of Economics, 95:185-199. 
Appendices 


\section{APPENDIX A}

We analyze the period-2 subgames, when there are no challengers in period 1 under marketing exclusivity. In this case, we have to consider three types of subgames in period 2 .

\section{A.1 Two challenges in period 2}

In this subgame, filing suit in period 2 delays entry till period 3 . In period 3 , the patent has expired so both generic firms enter, no matter what a court decision is. Thus, the incumbent's profit in period 3 is $\Pi^{T}$. But here is a curious possibility. Suppose that the incumbent loses the suit. Then, one generic firm is granted marketing exclusivity in period 3 and hence the incumbent earns the duopoly profit $\Pi^{D}$ instead of $\Pi^{T}$ in period 3. Therefore, the incumbent would rather file suit and intentionally lose the litigation. We conclude that filing infringement suit yields at least

$$
\Pi^{M}+\delta\left[\alpha \Pi^{T}+(1-\alpha) \Pi^{D}\right]+\delta^{2} \Delta
$$

to the incumbent. On the other hand, if it accommodates entry, only one generic firm enters under marketing exclusivity in period 2, yielding the following profit to the incumbent

$$
\Pi^{D}+\delta \Pi^{T}+\delta^{2} \Delta .
$$

The profit in (A.1) is greater than the profit in (A.2) and hence the incumbent files suit against both challengers. Therefore, each challenger's expected profit in period 2 is

$$
\left.e_{11}=-F+\delta\left[\alpha \Pi^{T}+(1-\alpha) \Pi^{D}\right) / 2\right]+\delta^{2} \Delta .
$$




\section{A.2 One challenger in period 2}

This case is similar to the previous subcase. If the incumbent sues this firm for patent infringement, there is no entry until period 3. Further, if the generic firm wins the litigation, that firm is granted marketing exclusivity in period 3. Thus, suing the challenger, the incumbent received the same profit as in (A.1). Accommodation yields the duopoly profit period 2 and the triopoly profit in all later periods, so the incumbent's profit is given by (A.2). Thus, the incumbent files infringement suit against the challenger in period 2. Therefore, the challenger's profit is

$$
e_{10}=-F+\delta\left[\alpha \Pi^{T}+(1-\alpha) \Pi^{D}\right]+\delta^{2} \Delta .
$$

The non-challenger's profit

$$
e_{01}=\delta \alpha\left(\Pi^{T}-F\right)+\delta^{2} \Delta-\delta^{2}(1-\alpha) F .
$$

\section{A.3 No challenges in period 2}

If both wait till period 3 to enter, each generic firm expects to make the profit equaling

$$
e_{00}=\delta(\Delta-F)
$$

Now, we can present the period-2 subgame in the matrix below.

\begin{tabular}{c|c|c|}
\multicolumn{1}{c}{$c$} & \multicolumn{1}{c}{$\bar{c}$} \\
\cline { 2 - 3 }$c$ & $e_{11}, e_{11}$ & $e_{10}, e_{01}$ \\
\cline { 2 - 3 } $\bar{c} \bar{c}$ & $e_{01}, e_{10}$ & $e_{00}, e_{00}$ \\
\cline { 2 - 3 } & &
\end{tabular}


To find the equilibrium, define $F_{X}$ implicitly by the equation $e_{11}-e_{01}=0$ and $F_{Y}$ by $e_{10}-e_{00}=0$. Substitution into $e_{i j}$ yields these values:

$$
\begin{aligned}
& F_{X} \equiv \delta(1-\alpha) \Pi^{D} /\{2(1-\delta)[1+\delta(1-\alpha)]\} \\
& F_{Y} \equiv \delta(1-\alpha)\left(\Pi^{D}-\Pi^{T}\right) /(1-\delta)
\end{aligned}
$$

Both $F_{X}$ and $F_{Y}$ decline toward zero as $\alpha$ goes to one. The next result presents the equilibrium outcomes of this subgame (proof is immediate from the above table).

Lemma 1 Suppose that neither generic firm challenges the patent in period 1. The equilibrium outcome in period 2 is as follows.

(A) If $F<\min \left\{F_{X}, F_{Y}\right\},(C, C)$ is the equilibrium outcome. As both generic firms challenge the patent in period 2, each generic firm's profit equals

$$
\delta^{2}\left[\alpha \Pi^{T}+(1-\alpha) \Pi^{D} / 2\right]+\delta^{3} \Delta-\delta F .
$$

(B) If $F>\max \left\{F_{X}, F_{Y}\right\},(\bar{C}, \bar{C})$ is the equilibrium outcome. As neither generic firm challenges the patent in period 2, each generic firm's profit is

$$
\delta^{2}(\Delta-F)
$$

(C) If $F \in\left|F_{X}-F_{Y}\right|,(C, \bar{C})$ or $(\bar{C}, C)$ is the equilibrium outcome. As either firm can be a challenger with an equal probability, each generic firm's expected profit is

$$
\begin{aligned}
& \delta^{2} \alpha \Pi^{T}+\delta^{2}(1-\alpha) \Pi^{D} / 2 \\
& \quad+\delta^{3} \Delta-\left[\delta+\delta^{2} \alpha+\delta^{3}(1-\alpha)\right] F / 2 .
\end{aligned}
$$

The relative size of $F_{X}$ and $F_{Y}$ plays a crucial role in this subgame. The next lemma relates these functions to the key parameters of the model. 
Lemma $2 F_{X}>F_{Y}$ if and only if $\delta(1-\alpha)<\left(\Pi^{T}-\Pi^{D} / 2\right) /\left(\Pi^{D}-\Pi^{T}\right)$.

Proof. The conclusion follows from $F_{X}-F_{Y}=\left\{\Pi^{D} / 2-\left(\Pi^{D}-\Pi^{T}\right)[1+\delta(1-\alpha)]\right\} \delta(1-$ $\alpha) /\{(1-\delta)[1+\delta(1-\alpha)]\}$.

Note that $\left(\Pi^{T}-\Pi^{D} / 2\right) /\left(\Pi^{D}-\Pi^{T}\right) \in(0,1)$ under assumption 1 . The next lemma follows immediately from Lemma 1.

Lemma 3 (A) If $\delta>\left(\Pi^{T}-\Pi^{D} / 2\right) /\left(\Pi^{D}-\Pi^{T}\right)$, there is $\hat{\alpha} \equiv 1-\left(\Pi^{T}-\Pi^{D} / 2\right) /\left[\delta\left(\Pi^{D}-\right.\right.$ $\left.\left.\Pi^{T}\right)\right] \in(0,1)$ so that (i) $F_{X}<F_{Y}$ for $\alpha<\hat{\alpha}$; (ii) $F_{X}=F_{Y}$ for $\alpha<\hat{\alpha}$; (iii) $F_{X}>F_{Y}$ for $\alpha>\hat{\alpha}$. (B) If $\delta \leq\left(\Pi^{T}-\Pi^{D} / 2\right) /\left(\Pi^{D}-\Pi^{T}\right), F_{X}>F_{Y}$ for all $\alpha \in(0,1)$.

The two cases defined in Lemma 3 are illustrated in Figures A1 and A2 below.

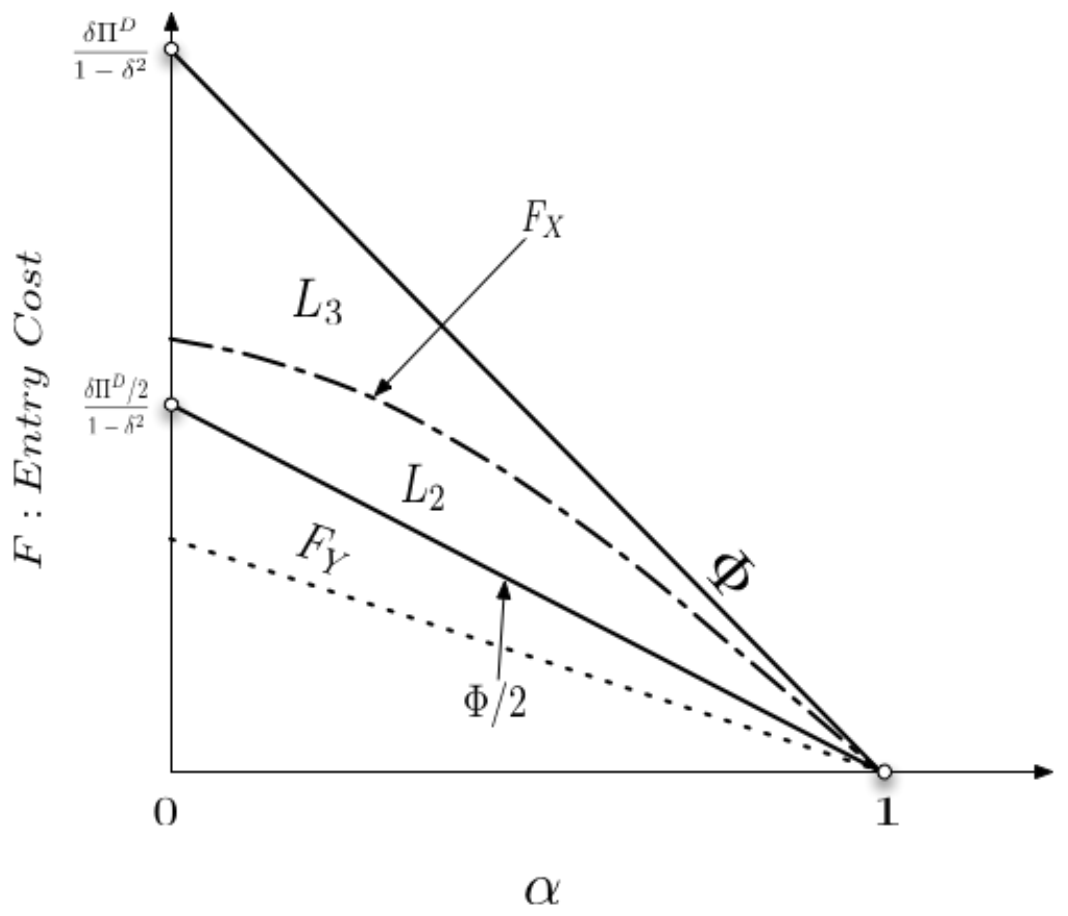

Figure A.1: $\delta \leq\left(\Pi^{T}-\Pi^{D} / 2\right) /\left(\Pi^{D}-\Pi^{T}\right)$ 


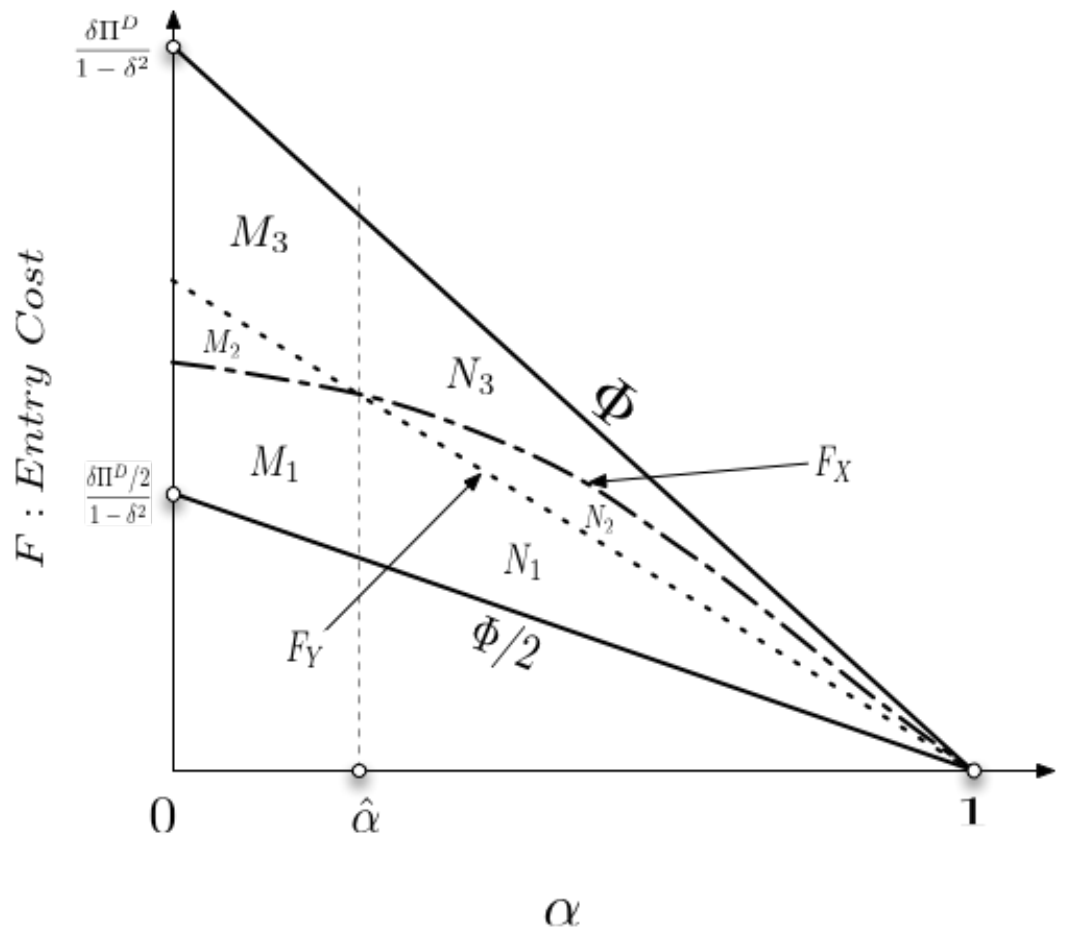

Figure A.2: $\delta>\left(\Pi^{T}-\Pi^{D} / 2\right) /\left(\Pi^{D}-\Pi^{T}\right)$ 


\section{APPENDIX B}

\section{PROOF OF PROPOSITION 1.2}

The first-stage simultaneous-move game between two generic firms as follows:

\begin{tabular}{ccc|}
\multicolumn{1}{c}{$c$} & \multicolumn{1}{c}{$c$} \\
\cline { 2 - 3 }$c$ & $E_{11}, E_{11}$ & $E_{10}, E_{01}$ \\
\cline { 2 - 3 } $\bar{c} \bar{c}$ & $e_{01}, e_{10}$ & $e_{00}, e_{00}$ \\
\cline { 2 - 3 } & &
\end{tabular}

where the payoffs are

$$
\begin{aligned}
& E_{11} \equiv-F+\delta(1-\alpha) \Pi^{D} / 2+\delta^{2} \Delta, \\
& E_{10} \equiv-F+\delta(1-\alpha) \Pi^{D}+\delta^{2} \Delta, \\
& E_{01} \equiv \delta^{2}(\Delta-F),
\end{aligned}
$$

as derived in the text, whereas $E_{00}$ takes on these three separate values, derived in

Lemma 4 Case 1: $F<\min \left\{F_{X}, F_{Y}\right\}: E_{00} \equiv \delta^{2}\left[\alpha \Pi^{T}+(1-\alpha) \Pi^{D} / 2\right]+\delta^{3} \Delta-\delta F$ Case 2: $\min \left\{F_{X}, F_{Y}\right\}<F<\max \left\{F_{X}, F_{Y}\right\}: E_{00} \equiv \delta^{2}\left[\alpha \Pi^{T}+(1-\alpha) \Pi^{D} / 2\right]+$ $\delta^{3} \Delta-\delta F\left[1+\delta \alpha+\delta^{2}(1-\alpha)\right] / 2$

Case 3: $F>\max \left\{F_{X}, F_{Y}\right\}: E_{00} \equiv \delta^{2}(\Delta-F)$.

Proof of Proposition 2 has three parts: Part I: $(C, C)$ is the Nash equilibrium outcome of the above game if $E_{11}-E_{01} \geq 0$. Letting $E_{11}-E_{01}=0$ and solving for the value of $F$, we find that the above condition is expressed as $F \leq \Psi / 2$, where $\Psi / 2 \equiv\left(\delta(1-\alpha) \Pi^{D} / 2\right) /\left(1-\delta^{2}\right)$. Part II: Next, for either $(C, \bar{C})$ and $(\bar{C}, C)$ to be an equilibrium outcome, we must have $E_{10}-E_{00}>0$ and $E_{01}-E_{11}>0$. The latter inequality is written $F>\Phi / 2$ from the preceding discussion. The former involves the term $E_{00}$ and hence there are three cases from Appendix A to consider. The results also depend on the sign of $F_{X}-F_{Y}$. Further, calculations show that for a given $\alpha<1, \Phi>F_{X}=\delta(1-\alpha)\left(\Pi^{D} / 2\right) /\{(1-\delta)[1+\delta(1-\alpha)]\}>\Phi / 2$. 
Suppose first that $\delta<\left(\Pi^{T}-\Pi^{D} / 2\right) /\left(\Pi^{D}-\Pi^{T}\right)$ so $F_{X}>F_{Y}$ all $\alpha \in(0,1)$ by Lemma 3. Substituting the expressions from the above, we can express the condition $E_{10}-E_{00}>0$ as follows

Case 1: $F<F_{Y}$.

$$
F<\hat{F}_{1} \equiv \delta(1-\alpha)\left[\Pi^{D}(1-\delta / 2)+\delta \Pi^{T}\right] /(1-\delta)
$$

Case 2: $F_{Y}<F<F_{X}$.

$$
\begin{aligned}
F & <\hat{F}_{2} \\
& \equiv 2 \delta(1-\alpha)\left[\Pi^{D}(1-\delta / 2)+\delta \Pi^{T}\right] /\left\{(1-\delta)\left\{2-\delta\left[1+\delta \alpha+\delta^{2}(1-\alpha)\right]\right\}\right\} \\
& =\left(2 \hat{F}_{1}\right) /\left\{2-\left[1+\delta \alpha+\delta^{2}(1-\alpha)\right]\right\}
\end{aligned}
$$

Case 3: $F>F_{X}$.

$$
F<\Phi \equiv\left(\delta(1-\alpha) \Pi^{D}\right) /\left(1-\delta^{2}\right)
$$

Define the sets that correspond to the three cases

$$
\begin{aligned}
& L_{1}=\left\{(\alpha, F) \mid F>\Phi / 2, F<F_{1} \text { and } F<\hat{F}_{1}\right\}, \\
& L_{2}=\left\{(\alpha, F) \mid F>\Phi / 2, F_{Y}<F<F_{X} \text { and } F<\hat{F}_{2}\right\}, \\
& L_{3}=\left\{(\alpha, F) \mid F>\Phi / 2, F_{X}<\text { Fand } F<\Phi\right\},
\end{aligned}
$$

and let $L=L_{1} \cup L_{2} \cup L_{3}$. We can show that given the restriction on $\delta<\left(\Pi^{T}-\right.$ $\left.\Pi^{D} / 2\right) /\left(\Pi^{D}-\Pi^{T}\right), F_{Y}<\Phi / 2$ and hence $L_{1}=\emptyset$. Next, we have $F_{X}<\hat{F}_{2}$ so that $L_{2}=\left\{(\alpha, F) \mid \Phi / 2<F<F_{X}\right\}$. Finally, since $F>\Phi / 2$, we have $L_{3}=\left\{(\alpha, F) \mid F_{X}<\right.$ $F<\Phi\}$. Therefore, there is one challenger in the set $L=\{(\alpha, F) \mid \Phi / 2<F<\Phi\}$. This is illustrated in Figure A1 below.

Finally, consider the complementary case, where $\delta \geq\left(\Pi^{T}-\Pi^{D} / 2\right) /\left(\Pi^{D}-\Pi^{T}\right)$. Then, $F_{X}<F_{Y}$ for $\alpha<\hat{\alpha}, F_{X}=F_{Y}$ for $\alpha=\hat{\alpha}$ and $F_{X}>F_{Y}$ for $\alpha>\hat{\alpha}$ by Lemma 
3. First consider the subcase in which $\alpha<\hat{\alpha}$. Corresponding to the three cases above, define the three sets as follows:

$$
\begin{aligned}
& M_{1}=\left\{(\alpha, F) \mid F>\Phi / 2, F<F_{X} \text { and } F<\hat{F}_{1} ; \alpha<\hat{\alpha}\right\}, \\
& M_{2}=\left\{(\alpha, F) \mid F>\Phi / 2, F_{X}<F<F_{Y} \text { and } F<\hat{F}_{2} ; \alpha<\hat{\alpha}\right\}, \\
& M_{3}=\left\{(\alpha, F) \mid F>\Phi / 2, F_{Y}<F \text { and } F<\Phi ; \alpha<\hat{\alpha}\right\},
\end{aligned}
$$

and $M=M_{1} \cup M_{2} \cup M_{3}$. Given $\delta \geq\left(\Pi^{T}-\Pi^{D} / 2\right) /\left(\Pi^{D}-\Pi^{T}\right)$, we have $F_{Y}>\Phi / 2$. Since $\hat{F}_{1}>F_{Y}{ }^{1}{ }^{1} M_{1}=\left\{(\alpha, F) \mid \Phi / 2<F<F_{X} ; \alpha<\hat{\alpha}\right\}$. Next, we want to show that $\hat{F}_{2}>F_{Y}$. Since the denominator of $\hat{F}_{2}$ is greater than that of $F_{Y}$, we only need to show that the numerator of $\hat{F}_{2}$ exceeds that of $F_{Y}$, which is true since

$$
\Pi^{D}+\delta\left(\Pi^{T}-\Pi^{D} / 2\right)>\Pi^{D}-\Pi^{T}
$$

Therefore, $M_{2}=\left\{(\alpha, F) \mid F_{X}<F<F_{Y} ; \alpha<\hat{\alpha}\right\}$. Finally, since $F_{Y}<\Phi$, we have $M_{3}=\left\{(\alpha, F) \mid F_{Y}<F<\Phi ; \alpha<\hat{\alpha}\right\}$. In conclusion, $M=\{(\alpha, F) \mid \Phi / 2<F<\Phi ; \alpha<$ $\hat{\alpha}\}$.

Consider next the subcase in which $\alpha>\hat{\alpha}$. Corresponding to the three cases above, define the three sets:

$$
\begin{aligned}
& N_{1}=\left\{(\alpha, F) \mid F>\Phi / 2, F<F_{Y} \text { and } F<\hat{F}_{1} ; \alpha>\hat{\alpha}\right\}, \\
& N_{2}=\left\{(\alpha, F) \mid F>\Phi / 2, F_{Y}<F<F_{X} \text { and } F<\hat{F}_{2} ; \alpha>\hat{\alpha}\right\}, \\
& N_{3}=\left\{(\alpha, F) \mid F>\Phi / 2, F_{X}<F \text { and } F<\Phi ; \alpha>\hat{\alpha}\right\}
\end{aligned}
$$

and $N \equiv N_{1} \cup N_{2} \cup N_{3}$. For $N_{1}$, we have $F_{Y}>\Phi / 2$. We also have $F_{Y}<\hat{F}_{1}$. Hence, $N_{1}=\left\{(\alpha, F) \mid \Phi / 2<F<F_{Y} ; \alpha>\hat{\alpha}\right\}$. Next, $\hat{F}_{2}>F_{X}$. Therefore, $N_{2}=$

\footnotetext{
${ }^{1}$ Proof of $\hat{F}_{1}>F_{Y}$.

Proof. $(1-\delta) \hat{F}_{1}>\delta(1-\alpha) \Pi^{D}>\delta(1-\alpha)\left(\Pi^{D}-\Pi^{T}\right)=(1-\delta) F_{Y}$.
} 
$\left\{(\alpha, F) \mid F_{Y}<F<F_{X} ; \alpha>\hat{\alpha}\right\}$. Finally, since $F_{X}>\Phi / 2, N_{3}=\left\{(\alpha, F) \mid F_{X}<\right.$ $F<\Phi ; \alpha>\hat{\alpha}\}$. Hence, $N=\{(\alpha, F) \mid \Phi / 2<F<\Phi ; \alpha>\hat{\alpha}\}$. Finally, suppose $\alpha=\hat{\alpha}$ so that $F_{X}=F_{Y}$ by Lemma 3 . By continuity of $F_{X}$ and $F_{Y}$, we can show that there is one challenger in the set $N^{\prime}=\{(\alpha, F) \mid \Phi / 2<F<\Phi ; \alpha=\hat{\alpha}\}$. Thus, $M \cup N \cup N^{\prime}=\{(\alpha, F) \mid \Phi / 2<F<\Phi ; \alpha \in(0,1)\}$. This is illustrated in Figure A2.

Finally, $(\bar{C}, \bar{C})$ is the Nash equilibrium outcome if and only if $E_{10}-E_{00}<0$ and $E_{11}-E_{01}<0$. These are complementary to the conditions under which the other equilibrium outcomes considered above do not occur, and hence is represented by the area above the line $F=\Phi$. Furthermore, Lemma $1 \mathrm{~B}$ shows that there are no challengers in period 2, either. Q.E.D. 


\section{APPENDIX C}

The difference in profit $\pi^{*}(m)-\left(\pi_{1}^{*}+m \pi_{j}^{*}\right)$ has the same sine as the expression in (C.1).

$$
\begin{aligned}
& g /[g(n-m+1) 2-(n-m) 2]-g /\left[g(n+1)^{2}-n^{2}\right] \\
&-m\left[g(n+1)^{2}-n^{2}-n\right]^{2} /\left\{\left[g(n+1)^{2}-n^{2}\right]^{2}(n+1)^{2}\right\} \\
&=g /\left[g(n-m+1)^{2}-(n-m)^{2}\right]-g /\left[g(n+1)^{2}-n^{2}\right] \\
&-m[g(n+1)-n]^{2} /\left[g(n+1)^{2}-n^{2}\right]^{2} \\
&=g / A-g / B-m C / B^{2},
\end{aligned}
$$

where

$$
\begin{aligned}
& A \equiv g(n-m+1)^{2}-(n-m)^{2}, \\
& B \equiv g(n+1)^{2}-n^{2}, \\
& C \equiv[g(n+1)-n]^{2} .
\end{aligned}
$$

Therefore, the sign of (C.1) depends on the sign of

$$
g(B-A) B-m A C
$$

Substitution yields

$$
\begin{aligned}
B-A & =\left[g(n+1)^{2}-n^{2}\right]-\left[g(n-m+1)^{2}-(n-m)^{2}\right] \\
& =[g(2 n+2-m)-(2 n-m)] m .
\end{aligned}
$$

Thus, we can cancel out $m$ in (C.2) (meaning that when $m=1$ merger is degenerate; the R\&D firm merges with itself, and hence there is gain or loss from the merger). The remaining terms from (C.2) after the cancellation can be written as:

$$
\begin{aligned}
& g[g(2 n+2-m)-(2 n-m)] B-\left[g(n-m+1)^{2}-(n-m)^{2}\right] C \\
= & g\{g[2 n(1-u)+2]-2 n(1-u)\} B-\left\{g[n(1-u)+1]^{2}-n^{2}(1-u)^{2}\right\} C
\end{aligned}
$$


where $u=m / n$. Letting $b=1-u$, we can rewrite (C.3) as

$$
\begin{aligned}
& g(g 2 n b+2 g-2 n b) B-\left[g(n b+1)^{2}-n^{2} b^{2}\right] C \\
= & \left(g^{2} 2 n b+2 g^{2}-2 g n b\right) B-\left[(g-1) n^{2} b^{2}+2 g n b+g\right] C \\
= & F(b)
\end{aligned}
$$

$F(b)$ is quadratic in $b$ and hence can be expressed as: $F(b)=\mu_{2} b^{2}+\mu_{1} b+\mu$ with coefficients

$$
\begin{aligned}
& \mu_{2}=-C(g-1) n^{2} \\
& \mu_{1}=2 g n[(g-1) B-C] \\
& \mu=g[2 g B-C]
\end{aligned}
$$

Substitution and calculations shows that $(g-1) B-C<0$ so that $\mu_{1}<0$ and $2 g B-C>0$. Thus, $F(b)$ has one positive root and one negative root. Also, by definition, m ranges from 1 to $n-1$, so $u$ ranges from $1 / n$ to $(n-1) / n$. Hence, $b$ runs from $(n-1) / n$ back to $1 / n$. When $b=1 / n$, we have a monopoly merger, which is profitable. That is, $F(1 / n)>0$. When $b=(n-1) / n$, we have that $m=1$. Therefore, if $F((n-1) / n)>0, F(b)>0$ on $b \in[1 / n, n /(n-1)]$ and hence merger is profitable for all $m$ and all $n$. Substituting $m=1$ in (C.3) yields $H(g, n)=g[g(2 n+1)-(2 n-1)]\left[g(n+1)^{2}-n^{2}\right]-\left[g n^{2}-(n-1)^{2}\right][g(n+1)-n]^{2}$ We thus seek condition $H(g, n) \geq 0$, subject to the limit on $g: g \geq n /(n+1)$. The range of $g$ for which $H(g, n)>0$ depends on $n$. For small values of $n$, condition $H(g, n) \geq 0$ holds in wider ranges of $g$, but the range of $g$ narrows and approaches $g=1$ as $n$ goes to infinity. Calculations yields the following values for the range of $g$ in which condition $H(g, n) \geq 0$ holds. 


\begin{tabular}{|c|c|c|}
\hline $\mathrm{n}$ & Lower limit of $g$ & Upper limit of $g$ \\
\hline 3 & 0.56 & 3.05 \\
4 & 0.64 & 1.73 \\
5 & 0.69 & 1.43 \\
6 & 0.73 & 1.31 \\
7 & 0.76 & 1.24 \\
8 & 0.88 & 1.19 \\
9 & 0.89 & 1.16 \\
10 & 0.82 & 1.14 \\
20 & 0.90 & 1.05 \\
50 & 0.98 & 1.02 \\
100 & 0.99 & 1.01 \\
\hline
\end{tabular}

Table C.1: The range of $g$ narrows to 1 as $n \rightarrow \infty$. 
VITA

\section{JIANGYUN WAN}

2006

2010

$2011-2015$
B.A., Engineering Management

Hubei University

Wuhan, Hubei, China

M.S., Economics

Florida International University

Miami, Florida

Doctoral Candidate, Economics

Florida International University

Miami, Florida International University

\section{PRESENTATIONS}

Wan, J., (April, 2014). Patents and entry competition in the pharmaceutical industry: The role of marketing exclusivity. Paper presented at the Economics Department, Florida International University.

Wan, J., (October, 2014). Why authorized generics: Theoretical and empirical investigations. Paper presented at the Economics Department, Florida International University. 